\title{
Contornos Deformáveis Paramétricos Adaptativos
}

\author{
Anderson Marques de Santana
}

Tese apresentada à Escola de Engenharia de São Carlos da Universidade de São Paulo, como parte dos requisitos para obtenção do título de Doutor em Engenharia Elétrica

Orientador: Prof. Tit. Dr. Ruy Alberto Corrêa Altafim 
AUTORIZO A REPRODUÇÄO E DIVULGAÇÄO TOTAL OU PARCIAL DESTE TRABALHO, POR QUALQUER MEIO CONVENCIONAL OU ELETRÔNICO, PARA FINS DE ESTUDO E PESQUISA, DESDE QUE CITADA A FONTE.

Ficha catalográfica preparada pela Seção de Tratamento da Informação do Serviço de Biblioteca - EESC/USP

\begin{tabular}{|l|} 
Santana, Anderson Marques de \\
Contornos deformáveis paramétricos adaptativos $/$ \\
Anderson Marques de Santana ; orientador Ruy Alberto \\
Corrêa Altafim. -- São Carlos, 2010. \\
Tese (Doutorado-Programa de Pós-Graduação em \\
Engenharia Elétrica e Área de Concentração em Sistemas \\
Elétricos de Potência) - Escola de Engenharia de São \\
Carlos da Universidade de São Paulo, 2010. \\
1. Processamento de sinais. 2. Contornos deformáveis. \\
Otimização. I. Título.
\end{tabular}


FOLHA DE JULGAMENTO

Candidato(a): Engenheiro ANDERSON MARQUES DE SANTANA.

Tese defendida e julgada em 28/05/2010 perante a Comissão Julgadora:
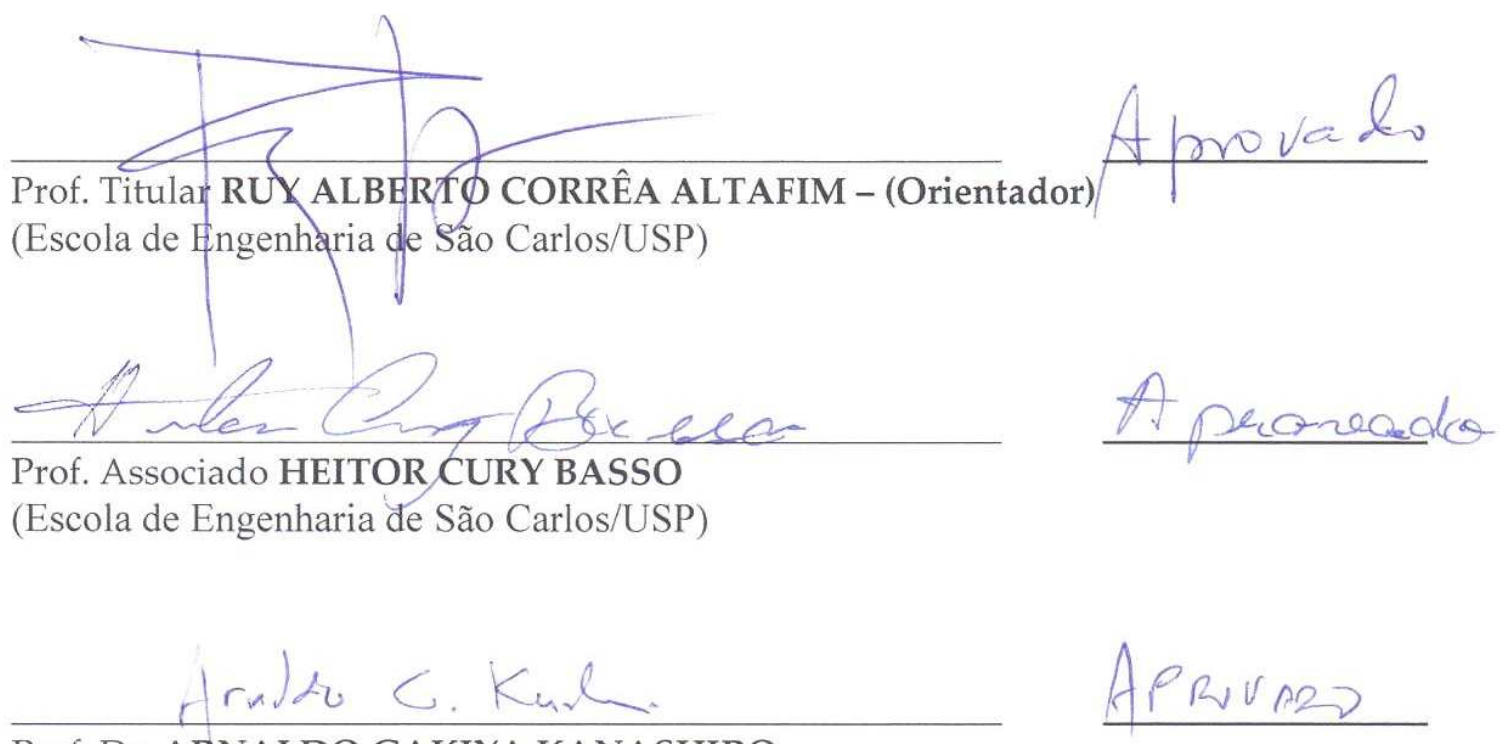

Prof. Dr. ARNALDO GAKIYA KANASHIRO

(Instituto de Eletrotécnica e Energia/USP)

Prof ${ }^{a}$. Dra ${ }^{\mathrm{a}}$. MARIA VIRGINIA GELFUSO

Aprovade

(Universidade Federal de Itajubá/UNIFEI)

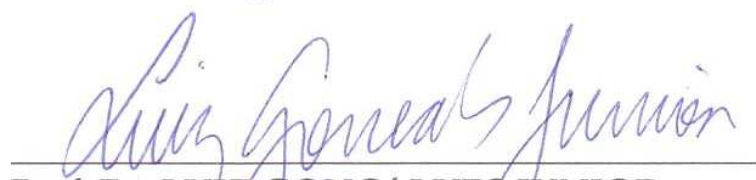

Aprovapo

Prof. Dr. LUIZ GONÇALVES JUNIOR

(Universidade Estadual Paulista "Julio de Mesquita Filho"/UNESP/Campus de Bauru)

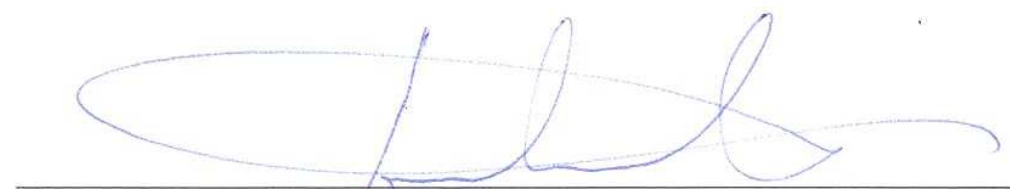

Prof. Titular GERALDO ROBERTO MARTINS DA COSTA Coordenador do Prograna de Pós-Graduação em Engenharia Elétrica e Presidente da Comissão de Pós-Graduação 
Dedicatória

À memória do meu amado pai Natal Joviniano de Santana. 


\section{A Deus;}

a minha família pela referência e suporte incondicionais;

a minha esposa pelo amor e compreensão;

ao meu mestre Professor Titular Dr. Ruy Alberto Correa Altafim pelo acolhimento, atenção e orientação sem os quais este trabalho não seria possível;

ao meu sogro José Roberto Fernandes de Oliveira pelo estímulo contínuo; aos meus amigos pelos momentos compartilhados;

e, se houver de ser irrogada alguma culpa pelas eventuais ausências nesta lista, que seja à minha mente ocupada e não ao meu coração profundamente grato a todos. 



\section{Sumário}

Lista de Figuras vii

Lista de Símbolos $\quad$ xi

Resumo xiii

$\begin{array}{ll}\text { Abstract } & \text { Xv }\end{array}$

1 Introdução 1

1.1 Organização do Texto . . . . . . . . . . . . . . 6

$\begin{array}{lll}2 & \text { Estado da Arte } & 7\end{array}$

2.1 Contornos Deformáveis . . . . . . . . . . . . . 8

2.2 Modelos Deformáveis Paramétricos . . . . . . . . . . . . 9

2.3 Formulação por Minimização da Energia . . . . . . . . . . . . . 10

2.3.1 Modelos Deformáveis à Luz do Cálculo Variacional . . . . 12

2.4 Formulação Dinâmica . . . . . . . . . . . . . . . . . . . . . 22

2.5 Forças Externas . . . . . . . . . . . . . . . . . . . . 22

2.6 Força Potencial Gaussiana . . . . . . . . . . . . . . . . . . . . 23

2.7 Força Potencial Gaussiana Multi Escala . . . . . . . . . . . . . 26

2.8 Força Distância . . . . . . . . . . . . . . . . . . . 27

2.9 Força Distância Dinâmica . . . . . . . . . . . . . . . . . . . 29

2.10 Força Balão . . . . . . . . . . . . . . . . . . . . 30

2.11 Gradient Vector Flow . . . . . . . . . . . . . . . . . . . 33

3 Solução Proposta 35

3.1 Corrugação . . . . . . . . . . . . . . . . . . . 4 40

3.2 Caracterização Local . . . . . . . . . . . . . . . . . . . . . . . 42 
3.2 .1 Avanço z(s) . . . . . . . . . . . . . . . . . 43

3.2 .2 Mérito $\mathrm{h}(\mathrm{s}) \ldots \ldots \ldots \ldots$. . . . . . . . . . . . . 43

3.3 Corrugação Propriamente Dita . . . . . . . . . . . . . . . . 50

4 Resultados e Discussões

4.1 Banco de Imagens . . . . . . . . . . . . . . . . . . . 53

4.2 Imagem Sintética Simples 1 - SS1 . . . . . . . . . . . . . . 55

4.3 Imagem Sintética Complexa 1 - SC1 . . . . . . . . . . . . . 57

4.4 Imagem Sintética Complexa 2 - SC2 . . . . . . . . . . . . . 59

4.5 Imagem Sintética Complexa 3 - SC3 . . . . . . . . . . . 61

4.6 Análise dos Resultados . . . . . . . . . . . . . . . . . 63

4.7 Análise dos Resultados Quanto às Funções de Mérito . . . . . . . 66

$\begin{array}{lll}5 & \text { Conclusões } & 69\end{array}$

5.1 Trabalhos Futuros . . . . . . . . . . . . . . . 70

$\begin{array}{ll}\text { Referências Bibliográficas } & 73\end{array}$ 


\section{Lista de Figuras}

1 Espaçamentos e adensamentos inadequados em imagem mamográfica real ............................ 1

1.1 Espaçamentos e adensamentos inadequados em imagem mamográfica real ......................... 5

2.1 Relação entre $y(x)$ (azul), $y^{*}(x)$ (preto pontilhado) e $u(x)$ (preto

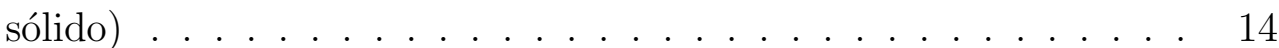

2.2 Máscaras de convolução gaussianas de dimensão 20 x 20 e desvios padrões: $\sigma=1$ (a), $\sigma=2$ (b), $\sigma=4$ (c) e $\sigma=8$ (d) . . . . . . 24

2.3 Imagem sintética complexa $(\mathrm{SC}) \ldots \ldots . \ldots . \ldots . . \ldots 24$

2.4 Função potencial de energia gaussiana obtida da imagem da Figura 2.3 pelo uso das máscaras de convolução na Figura $2.2 \ldots$. . . . .

2.5 Campo de forças potencial gaussiana obtidas da imagem 2.3 por convolução com máscaras gaussianas de desvios padrão $\sigma=16 \mathrm{e}$ dimensão 20x20 . . . . . . . . . . . . . . . . . .

2.6 Curvas de nível da intensidade da força potencial gaussiana obtida por máscaras gaussianas de variados desvios padrão . . . . . . . .

2.7 Imagem sintética complexa SC-5 e o mapa de distâncias associado

2.8 Campo de forças distância . . . . . . . . . . . . . . . . . . . . . . 29

2.9 Contorno (a) e campos de força distância original (b) e normalizado (c) em concavidade 
3.1 Evolução de contorno deformável sob ação de força GVF . . . . . 36

3.2 Trajetória descritas pelos pontos do contorno deformável em sua evolução sob ação exclusiva das forças internas e externas: (*) pontos conforme iniciados, (-) suas trajetórias e $(+)$ suas posições ao término das iterações . . . . . . . . . . . . . . . . . . 37

3.3 Detalhe da trajetória descrita pelos pontos do contorno deformável em sua evolução sob ação exclusiva das forças internas e externas: (-) trajetória dos pontos ao longo das iterações . . . . . . . . . . . 38

3.4 Trajetória descritas pelos pontos do contorno deformável em sua evolução sob ação complementar da força proposta: $(*)$ pontos conforme iniciados, (-) suas trajetórias e (+) suas posições ao término das iterações . . . . . . . . . . . . . . . . . . . . . . . . 39

3.5 Contornos identificados por uso da solução proposta e da snake GVF 39

3.6 Metodologia proposta . . . . . . . . . . . . . . . . . 40

3.7 Resultado qualitativo da força de corrugação . . . . . . . . . . . . 41

3.8 Domínio espacial do sinal e espaço de parâmetros . . . . . . . . . 42

3.9 Função de mérito pseudo-curvatura como função da inclinação dos segmentos sucessor $\theta_{f}$ e antecessor $\theta_{i}$ do ponto . . . . . . . . 44

3.10 Contorno circular e espaço de parâmetro para a função de mérito pseudo-curvatura . . . . . . . . . . . . . . 45

3.11 Contorno elipsoidal e espaço de parâmetro para a função de mérito pseudo-curvatura ..................... 45

3.12 Contorno em forma de feijão e espaço de parâmetro para a função de mérito pseudo-curvatura . . . . . . . . . . . 46

3.13 Contorno fusiforme e espaço de parâmetro para a função de mérito pseudo-curvatura . . . . . . . . . . . . . . . 46 
3.14 Contorno em forma de fechadura e espaço de parâmetro para a função de mérito pseudo-curvatura . . . . . . . . . . . . 47

3.15 Contorno circular e espaço de parâmetro para a função de mérito rugosidade . . . . . . . . . . . . . . . . . . . . . 48

3.16 Contorno elipsoidal e espaço de parâmetro para a função de mérito rugosidade . . . . . . . . . . . . . . . . . . . 48

3.17 Contorno em forma de feijão e espaço de parâmetro para a função de mérito rugosidade . . . . . . . . . . . . . . . . . 49

3.18 Contorno fusiforme e espaço de parâmetro para a função de mérito rugosidade . . . . . . . . . . . . . . . . . . . . 49

3.19 Contorno em forma de fechadura e espaço de parâmetro para a função de mérito rugosidade . . . . . . . . . . . . . . . . . . . 50

4.1 Imagem sintética simples SS1 f . . . . . . . . . . . . . . . 54

4.2 Imagem sintética complexa SC1 . . . . . . . . . . . . . . 54

4.3 Imagem sintética complexa $\mathrm{SC} 2 \ldots \ldots$. . . . . . . . . . . . . 54

4.4 Imagem sintética complexa SC3 . . . . . . . . . . . . . . . 55

4.5 Contorno da figura SS1 identificado por modelo deformável: GVF (azul) e corrugado com função de mérito equalizadora (vermelho) 56

4.6 Contorno da figura SS1 identificado por modelo deformável: GVF (azul) e corrugado com função de mérito pseudo-curvatura (vermelho) . . . . . . . . . . . . . . . . 56

4.7 Contorno da figura SS1 identificado por modelo deformável: GVF (azul) e corrugado com função de mérito rugosidade (vermelho)

4.8 Contorno da figura SC1 identificado por modelo deformável: GVF (azul) e corrugado com função de mérito equalizadora (vermelho) 58 
4.9 Contorno da figura SC1 identificado por modelo deformável: GVF (azul) e corrugado com função de mérito pseudo-curvatura (vermelho) . . . . . . . . . . . . . . . . . 58

4.10 Contorno da figura SC1 identificado por modelo deformável: GVF (azul) e corrugado com função de mérito rugosidade (vermelho)

4.11 Contorno da figura SC2 identificado por modelo deformável: GVF (azul) e corrugado com função de mérito equalizadora (vermelho) 60

4.12 Contorno da figura SC2 identificado por modelo deformável: GVF (azul) e corrugado com função de mérito pseudo-curvatura (vermelho) . . . . . . . . . . . . . . . . . . 60

4.13 Contorno da figura SC2 identificado por modelo deformável: GVF (azul) e corrugado com função de mérito rugosidade (vermelho)

4.14 Contorno da figura SC3 identificado por modelo deformável: GVF (azul) e corrugado com função de mérito equalizadora (vermelho)

4.15 Contorno da figura SC3 identificado por modelo deformável: GVF (azul) e corrugado com função de mérito pseudo-curvatura (vermelho) . . . . . . . . . . . . . . . .

4.16 Contorno da figura SC1 identificado por modelo deformável: GVF (azul) e corrugado com função de mérito rugosidade (vermelho)

4.17 Trajetória descrita por contornos deformáveis: $(\longleftarrow)$ campo de força externa, (- verde) Snake GVF e (- azul) Snake Corrugada . . . . . 64

4.18 Disponibilização de pontos para investigar regiões do elemento de interessa na imagem não contempladas pela snake GVF: $(\leftarrow)$ campo de força externa, (- verde) trajetórias dos pontos da Snake GVF e (- azul) trajetória dos pontos da Snake corrugada . . . . .

4.19 Méritos calculados por uso das funções pseudo-curvatura e rugosidade para um contorno elíptico . . . . . . . . . . . . 
4.20 Méritos calculados por uso das funções pseudo-curvatura e rugosidade para contorno formado por duas semi-elipses concordantes . 68 



\section{Lista de Símbolos}

$\mathbb{R}^{n} \quad$ conjunto dos vetores de dimensão $n$

$\mathbb{R}^{n \times m}$ conjunto das matrizes de dimensão $n \times m$

$\Gamma(x, y) \quad$ elemento da imagem $\Gamma$ com coordenada $(x, y)$

$B_{\Gamma} \quad$ conjunto dos pontos pertencentes às bordas da imagem $\Gamma$

$s \quad$ parâmetro comprimento de arco

$\boldsymbol{X}(s) \quad$ contorno deformável parametrizado pelo comprimento de arco s

$\boldsymbol{x}(s) \quad$ coordenada horizontal do ponto constituinte do contorno deformável parametrizada por comprimento de arco s

$\boldsymbol{y}(s) \quad$ coordenada vertical do ponto constituinte do contorno deformável parametrizada por comprimento de arco $\mathrm{s}$

$\boldsymbol{\epsilon}(\boldsymbol{X}) \quad$ função energia

$\boldsymbol{I}(\boldsymbol{X}) \quad$ componente interna da função energia

$\boldsymbol{P}(\boldsymbol{X}) \quad$ componente externa da função energia

$\boldsymbol{\alpha}(s) \quad$ coeficiente de alongamento da componente intera da energia do contorno deformável paramético

$\boldsymbol{\beta}(s) \quad$ coeficiente de dobramento da componente intera da energia do contorno deformável paramético

$\boldsymbol{P}_{\boldsymbol{d}}(\boldsymbol{x}, \boldsymbol{y}) \quad$ função energia potencial distância associada ao elemento de coordenada $(\mathrm{x}, \mathrm{y})$ na imagem

$f_{d}(x, y) \quad$ força potencial distância correspondente à coordenada $(\mathrm{x}, \mathrm{y})$ da imagem

SC-x $\quad$ sintética complexa de número $\mathrm{x}$ 
GVF Gradient Vector Flow

$U V(x, y) \quad$ campo de força GVF

$u(x, y) \quad$ componente horizontal do campo GVF UV(x,y)

$v(x, y) \quad$ componente vertical do campo GVF UV(x,y)

$f_{d}(x, y) \quad$ força potencial distância correspondente à coordenada $(\mathrm{x}, \mathrm{y})$ da imagem

$f_{d}(x, y) \quad$ força potencial distância correspondente à coordenada $(\mathrm{x}, \mathrm{y})$ da imagem

$\vec{n}(s) \quad$ vetor normal ao contorno no comprimento normalizado s 


\section{Resumo}

Santana A. M. Contornos Deformáveis Paramétricos Adaptativos. São Carlos, 2010, Tese (Doutorado) - Escola de Engenharia de São Carlos, Universidade de São Paulo.

Segundo a definição original de MCINERNEY \& TERZOPOULOS (1995), modelos deformáveis são curvas ou superfícies formadas por pontos conectados que simulam corpos elásticos. Por superarem muitas limitações associadas ao procedimento manual e às técnicas tradicionais de processamento, os contornos deformáveis têm se popularizado. Ainda que o uso dos contornos deformáveis seja vasto e crescente, aspectos relevantes da teoria ainda têm demandado atenção. Muitas referências têm sido feitas às limitações da técnica impostas sobretudo pelo seu processo evolutivo. A convergência a mínimos locais e o agrupamento indesejado de pontos, por exemplo, limitam o emprego da técnica em cenários ruidosos e complexos como os encontrados em reservatórios de petróleo. Esse trabalho apresenta uma abordagem inédita às limitações dos contornos deformáveis. Pela definição de um segundo problema de minimização são definidas distâncias ótimas dos pontos do contorno deformável segundo critério de optimalidade que contempla as particularidades do contorno buscado. Os resultados demonstram que a técnica proposta é provedora de maior enquadramento entre o contorno buscado e o identificado, define solução definitiva aos problemas do agrupamento e espalhamento indesejados de pontos, aumenta a efetividade dos contornos deformáveis em regiões côncavas e, em acréscimo, define metodologia unicamente capaz de dotar os contornos deformáveis de sensibilidade quanto às particulari- 
dades do contorno.

Palavras-Chave: Contornos Deformáveis, Otimização. 


\section{Abstract}

According to the original definition of Terzopoulos, deformable models are curves or surfaces formed by connected points that simulate elastic bodies. By overcoming many limitations associated with the manual procedure and the traditional techniques of processing, deformable contours have become popular. Although the use of deformable contours is vast and growing aspects of the theory still demand attention. Many references have been made to the limitations of the technique imposed by the process evolution process. The convergence to minimum and unwanted bundling points, for example, limit the use of the technic on noisy and complex scenarios as those found in oil reservoirs. This work presents a novel approach to the limitations of deformable contours. By the definition of a second problem of minimization are defined optimal distances of the points of deformable contour according to a optimality criterion that incorporates features of the contour sought. The results show that the proposed technique peovides a larger framework between the contour sought and identified, defines a permanent solution to the problems of grouping and unwanted scattering of points, increases the effectiveness of deformable contours in concave regions and, in addition, defines methodology only able to provide the contours deformable sensitivity about the peculiarities of the contour. Santana A. M. Adaptive Parametric Deformable Models . São Carlos, 2010 Thesis (Phd) - Escola de Engenharia de São Carlos, Universidade de São Paulo. 
Key-Words: Deformabel models, Optimization. 


\section{Capítulo 1}

\section{Introdução}

A identificação de formatos de objetos e, de modo mais geral, a modelagem de elementos de interesse, constam entre os procedimentos mais complexos e importantes em processamento de imagens e demais sinais em $\mathbb{R}^{n}$ [CHUANG \& LIE (2001)]. Sua utilização nas áreas das imagens médicas [VAN GINNEKEN et al. (2001), MCINERNEY \& TERZOPOULOS (1996)]e de alta tensão ${ }^{1}$, por exemplo, é ainda questão crucial e desafiadora. Na engenharia de petróleo, não obstante a modelagem confiável de frentes de avanço seja demanda de grande importâcia [JACOBSEN et al. (1995), NUNES et al. (2009), HALDAR et al. (2008), WENNBERG et al. (2001), LARTER et al. (2008), DIAZ et al. (2007), MENDEZ et al. (2005), GLIMM et al. (1983)], as limitações da técnica a tem desqualificado como solução. O grande esforço dedicado ao desenvolvimento e ao aprimoramento das técnicas e metodologias subjacentes é expressão da relevância do tema. Resultam deste empenho as técnicas de baixo nível como a detecção de bordas e o crescimento de regiões e as técnicas de alto nível como os contornos deformáveis, objeto deste trabalho.

As técnicas de baixo nível são bem caracterizadas pela simplicidade computacional. Esta propriedade, entretanto, é obtida ao custo da análise exclusiva das informações locais. Seu emprego em problemas mais complexos requer con-

\footnotetext{
${ }^{1}$ Classificação de superfícies quanto à hidrofobicidade [hidrofob]
} 
sideráveis níveis de intervenção de especialistas e é de difícil automatização. As técnicas de baixo nível são inviabilizadas também em situações nas quais, por conta da infinidade de possíveis formatos, dos ruídos inerentes à metodologia de aquisição, ou até mesmo do próprio funcionamento dos equipamentos, os contornos obtidos são mal definidos e descontínuos. Com efeito, ainda que convenientes a uma grande variedade de aplicações, as técnicas de baixo nível têm seu uso restrito aos problemas de menor complexidade. Este cenário define demanda por técnicas de alto nível e afigura os modelos deformáveis como solução particularmente útil [GOLDENSTEIN et al. (2004)].

Segundo a definição original de MCINERNEY \& TERZOPOULOS (1995), modelos deformáveis são curvas ou superfícies formadas por pontos conectados que simulam corpos elásticos. Constituem uma metodologia composta por conhecimentos nas áreas de geometria, física, computação e teoria da aproximação. Estes modelos consideram o contorno como uma estrutura conectada e possibilitam, por conseqüência, a incorporação de informações a priori acerca do formato buscado. A continuidade e a suavidade inerentes aos modelos podem compensar ruído, descontinuidades do contorno e outras irregularidades nas bordas do elemento buscado no sinal. Estas propriedades qualificam os modelos deformáveis como solução eficiente, robusta, elegante e compacta de se promover a descrição analítica dos contornos dos objetos. Sua formulação matemática constitui um mecanismo poderoso de associar aspectos ruidosos em imagens com modelos consistentes do objeto.

Por superarem muitas limitações associadas ao procedimento manual e às técnicas tradicionais de processamento, os contornos deformáveis têm se popularizado [PARAGIOS et al. (2004)]. A formulação dos contornos deformáveis possibilita a interação com processos em alto nível; a abordagem do contorno como um todo; o trato de imagens com contornos mais complexos, descontínuos e pouco definidos; e, em princípio, não depende de intervenções de especialistas. Sua aplicação em identificação de lesões de pele [ERKOL et al. (2005)], tumo- 
res mamários [HAMARNEH \& GUSTAVSSON (2000)], grasping ${ }^{2}$ e tracking ${ }^{3}$ são exemplos bastante ilustrativos de sua versatilidade.

A modelagem de contornos por uso dos modelos deformáveis, propriamente dita, se dá por um processo dinâmico de deformação do modelo. O processo iniciase pela definição do aspecto inicial do contorno e finaliza na sua conformação aos objetos de interesse. Ao fazê-lo, os modelos deformáveis definem amostras do contorno procurado. A parametrização das amostras, então, provê informações quanto à morfologia, orientação e posição para o processamento subseqüente em alto nível.

Ainda que o uso dos contornos deformáveis seja vasto e crescente, aspectos relevantes da teoria ainda têm demandado atenção. Muitas referências têm sido feitas às limitações da técnica impostas sobretudo pelo seu processo evolutivo YUNG (1997). Problemas como a demasiada sensibilidade à inicialização, a pequena efetividade em regiões côncavas [CHUANG \& LIE (2001), YUNG (1997)], o agrupamento indesejado de pontos [SEO et al. (2004)], a falta de garantia de convergência a mínimos globais, o arredondamento dos cantos e a incapacidade de tratar com aspectos complexos têm sido registrados por vários autores [VAN GINNEKEN et al. (2001)]. O grande esforço dedicado à melhoria destes aspectos da sua formulação original tem caracterizado a área dos contornos deformáveis como das mais vigorosas e promissoras na área do processamento de imagens.

As investigações conduzidas com foco na definição de novos modelos de forças externas tem se destacado dentre as muitas contribuições para a formulação dos modelos deformáveis. Dispõe-se hoje de modelos de força externa mais elaborados e provedores de campos de força de boa abrangência e qualidade. Contudo, ainda que responsáveis pela consecução de melhores resultados, as soluções propostas implicam no aparecimento de outros problemas e são inexpressivas no que tange à falta de sensibilidade da técnica às necessidades específicas das regiões

\footnotetext{
${ }^{2}$ procedimento de entrega ou saque por manipulador robótico

${ }^{3}$ detecção de objetos ou trajetórias em cenários dinâmicos
} 
do contorno. Com efeito, a limitação tem sido tratada pelo uso de contornos constituídos por maior número de pontos e, consequentemente, mais lentos.

Campos de força externa de grande qualidade foram propostos em solução às limitações dos contornos deformáveis. O gradient vector flow, por exemplo, apresenta propriedades que, mediante análise exclusiva da motivação do esquema, deveria conduzir fielmente o modelo deformável ao contorno. Este modelo de força tem sido aclamado com o campo de força externo de melhor qualidade e dominado a maioria das aplicações. Os problemas intrínsecos à formulação variacional dos contornos deformáveis, entretanto, não foram solucionados. A relevância do problema tem motivado investigações acerca de formulações mais complexas, pesadas e problemáticas. A Figura 3.1, por exemplo, ilustra uma sequência na qual constam estágios evolutivos de um contorno que converge para mínimos locais.

Ainda que sob ação de campos vetoriais de força externa de boa qualidade, pontos do contorno podem estacionar em mínimos locais demasiadamente próximos, ou em pontos desgarrados do contorno de interesse. Isto se deve ao fato de que a sua formulação original não contempla a análise da distância conveniente entre seus pontos. Também não se dispõe de metodologia capaz de avaliar a eventual inadequação de pontos espúrios ao contorno buscado. Com efeito, a snake evolui com a possibilidade de desprivilegiar regiões de contorno nas quais estes pontos são necessários.

Excepcionalmente no caso das snakes leves (com poucos pontos), esta desatenção ao posicionamento ótimo dos pontos ao longo da curva poligonal que constitui a snake implica em perdas apreciáveis da fidelidade na representação dos objetos de interesse. Como resultado, os contornos deformáveis tornam-se inadequados à aplicação em imagens com grandes concavidades e geometrias complexas, ou o fazem a custo da apreciável elevação no número de pontos constituintes para melhores representações de cantos. A Figura 1.1 ilustra tais ocorrências em uma imagem mamográfica real. 


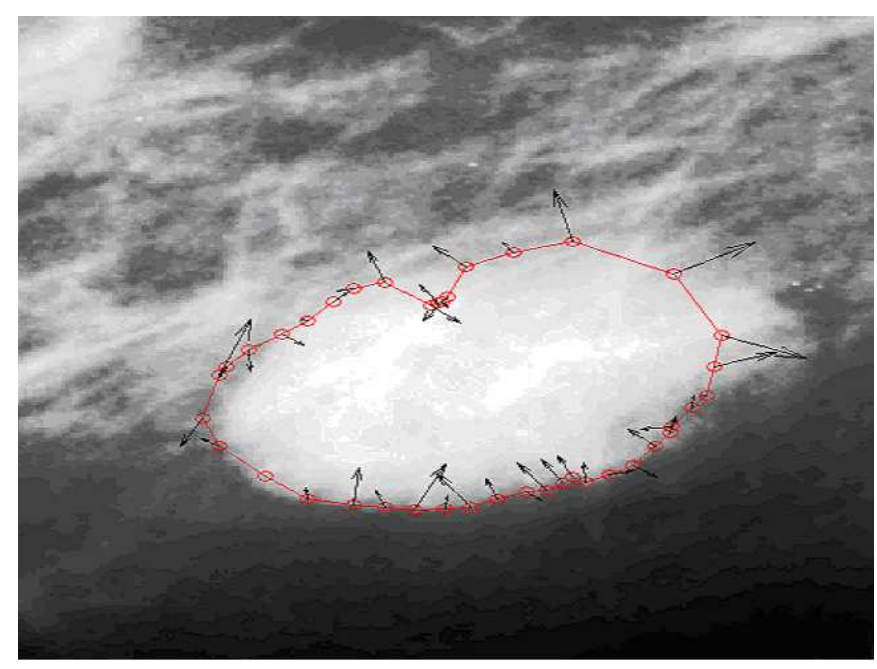

Figura 1.1: Espaçamentos e adensamentos inadequados em imagem mamográfica real

Estes trabalhos apresentaram grandes contribuições acerca da questão do espalhamento dos pontos mas sequer fazem referência a uma questão mais ampla que é a convergência ótima das snakes mais rápidas e leves, além de implicarem em mudanças profundas na abordagem proposta por Kass.

Este trabalho apresenta uma abordagem inédita às limitações dos contornos deformáveis. Propõe-se um segundo problema de minimização em solução ao qual são definidas distâncias ótimas dos pontos do contorno deformável segundo critério que contempla as particularidades do contorno buscado. A solução proposta é unicamente capaz de dotar o processo evolutivo de sensibilidade às demandas específicas das regiões do contorno e, conforme os resultados preliminares demonstram, é provedora de maior enquadramento entre o contorno buscado e o identificado, define solução definitiva aos problemas de agrupamento e espalhamento indesejados dos pontos e aumenta a efetividade dos contornos deformáveis em regiões côncavas. 


\subsection{Organização do Texto}

O texto foi dividido em seis capítulos. Este primeiro capítulo consiste de uma introdução ao trabalho com foco na breve caracterização do problema e de sua relevância. O segundo capítulo discorre sobre a formulação original dos contornos deformáveis de modo a prover os subsídios às considerações subsequentes e à contextualização do trabalho no cenário mais amplo das pesquisas congêneres. Os capítulos 3 e 4 apresentam a solução proposta e os resultados preliminares, respectivamente. O capítulo 5 registra a análise dos resultados e as conclusões preliminares e, por fim, o capítulo 6 referencia a bibliografia. 


\section{Capítulo 2}

\section{Estado da Arte}

A identificação de objetos em imagens pela deformação de modelos foi apresentada originalmente na década de 70. Em 1973 Fischler e Elschlager discorreram sobre a idéia no trabalho intitulado "The representation and matching of pictorial structures". Independentemente e no mesmo ano, Widrow abordou o tema em seu trabalho de título "The rubber-mask technique".

Mesmo tendo o princípio sido vislumbrado nos anos 70, a definição de contornos deformáveis pela conexão de nós e sua associação a um problema de minimização foi apresentada apenas em 1988 em solução a problemas mal apresen$\operatorname{tados}^{1}$ em processamento de imagens [WERUAGA et al. (2004)]. A extração de objetos em imagens pelo uso de curvas associadas a um processo de minimização foi descrita pela primeira vez por Kass, Witkin e Terzopoulos [KASS et al. (1988)] nesse mesmo ano. O tema tornou-se, a partir de então, uma das áreas mais importantes e prolíficas no processamento de imagens.

A proposição definiu abordagem promissora a limitações deveras restritivas das técnicas tradicionais. Ao mesmo tempo, entretanto, apresentou questões novas e mais complexas que relacionavam-se sobretudo com a implementação computacional da solução do problema variacional associado e com a sua relação com o processo evolutivo dos contornos deformáveis.

\footnotetext{
${ }^{1}$ Usualmente referidos por ill-posed problems, [BERTERO et al. (1988)]
} 
A conjunção entre a potencialidade dos contornos deformáveis e as limitações das técnicas disponíveis à ocasião conferiu aos contornos deformáveis notoriedade. Da atenção dedicada resultaram trabalhos propostos por vários autores [GOLDENSTEIN et al. (2004), CHUANG \& LIE (2001), SEO et al. (2004), VAN GINNEKEN et al. (2001), YUNG (1997)]. Contribuições relevantes foram responsáveis por evolução substancial na teoria segundo vários aspectos funcionais porém, a tarefa de fazer um conjunto de pontos representar um contorno em uma imagem é questão desafiadora [WILLIAMS \& SHAH (1992)]. A modelagem de frentes de avanço em rochas reservatório [GLIMM et al. (1983)], por exemplo, é inviabilizada pela natureza heterogênea e pelos níveis de ruído associados aos sinais argumento.

Esse capítulo é dedicado à contextualização do trabalho no cenário mais amplo das pesquisas congêneres. Com esse propósito será descrita a dinâmica evolutiva dos contornos deformáveis à luz de sua formulação matemática e, por fim, será caracterizado o problema objeto desta investigação pela confrontação entre as contribuições mais expressivas, suas questões motivadoras e as limitações remanescentes.

\subsection{Contornos Deformáveis}

Muitos termos são utilizados na literatura para referir os modelos deformáveis. Constam dentre estes: snakes [XU \& PRINCE (1998)], contornos ativos [WILLIAMS \& SHAH (1992),YUNG (1997)] e contornos deformáveis [GEIGER et al. (1995)]. Apesar das variadas denominações, existem apenas dois tipos de contornos deformáveis. De acordo com sua representação e implementação, os modelos deformáveis são classificados como paramétricos ou geométricos.

Modelos deformáveis paramétricos são aqueles nos quais a representação das curvas ocorre de forma paramétrica em uma formulação lagrangeana. Nos modelos deformáveis geométricos a representação ocorre implicitamente como curvas de nível de funções que evoluem segundo formulação euleriana. Os modelos de- 
formáveis paramétricos são baseados na teoria do cálculo variacional e os modelos deformáveis geométricos são baseados na teoria da evolução das curvas e implementados pelo método das curvas de nível [MALLADI et al. (1995)].

A formulação paramétrica é a mais antiga delas e tem sido utilizada extensivamente na última década [SEO et al. (2004), VAN GINNEKEN et al. (2001), CHUANG \& LIE (2001), METAXAS \& KAKADIARIS (1996), XU et al. (2000), ERKOL et al. (2005), PARAGIOS et al. (2004), WERUAGA et al. (2004), JALBA et al. (2004), LIE \& CHUANG (2001), PARK et al. (2001), XU \& PRINCE (1998)]. Esta representação permite interação direta com o modelo e pode levar a uma representação compacta para aplicações rápidas em tempo real. Uma grande variedade de modificações baseadas em conceitos físicos e nãofísicos foram propostas em solução às limitações desta formulação, entretanto, a adaptação da topologia do modelo como splitting ou merging, ainda é difícil por uso dos modelos deformáveis paramétricos.

Modelos deformáveis geométricos foram apresentados mais recentemente em solução às limitações dos modelos deformáveis paramétricos associadas às modificações topológicas. Por terem sua parametrização computada apenas após a deformação completa, os modelos deformáveis geométricos permitem fáceis adaptações topológicas. Contribuições recentes também têm sido propostas em melhoria de sua performance.

Por restrição ao objeto de estudo e sem perda de generalidade, o próximo tópico apresentará mais detalhadamente os modelos deformáveis paramétricos com referências mais amplas à sua formulação matemática.

\subsection{Modelos Deformáveis Paramétricos}

Matematicamente, um modelo deformável paramétrico é definido como uma curva fechada $X(s)=(x(s), y(s))$ que evolui no tempo sobre o domínio espacial da imagem, no qual o parâmetro comprimento de arco normalizado $s \in[0,1]$, $x(s)$ e $y(s) \in R$. Existem duas formulações para o processo evolutivo dos mo- 
delos deformáveis paramétricos²: a formulação por minimização da energia e a formulação dinâmica.

As formulações por minimização energética e dinâmica dos contornos deformáveis paramétricos são essencialmente iguais quanto à implementação mas, do ponto de vista formal, resultam de considerações teóricas iniciais diferentes. Os dois tópicos subseqüentes serão dedicados à descrição detalhada de suas particularidades.

\subsection{Formulação por Minimização da Energia}

O princípio da formulação dos modelos deformáveis paramétricos por minimização de energia é a associação da evolução do contorno à minimização de uma função energia definida sobre o domínio da imagem. A função energia $\varepsilon(X)$ é definida, conforme consta na equação 2.1, pela soma de uma componente interna $I(X)$ e uma componente externa ou potencial $P(X)$.

$$
\varepsilon(X)=I(X)+P(X)
$$

A componente interna da energia deve-se à curva propriamente dita e é função de seus parâmetros morfológicos dobramento e alongamento. O alongamento da curva é quantificado pelo termo derivativo de primeira ordem e o seu dobramento ${ }^{3}$ pela derivada de ordem dois.

A componente interna é definida conforme consta na equação 2.2 .

$$
I(X)=\frac{1}{2} \int_{0}^{1}\left(\alpha(s)\left|\frac{\partial X}{\partial s}\right|^{2}+\beta(s)\left|\frac{\partial^{2} X}{\partial s^{2}}\right|^{2}\right) d s
$$

Na prática, aos coeficientes $\alpha$ e $\beta$ da equação 2.2 são atribuídos valores cons-

\footnotetext{
${ }^{2}$ Formulações diferentes foram e têm sido apresentadas em solução às limitações originais dos contornos deformáveis paramétricos mas, por fins organizacionais, elas serão mencionadas mais oportunamente adiante.

${ }^{3}$ Do termo inglês bending. É também traduzido para o português como curvamento
} 
tantes que são definidos como função do conhecimento a priori de propriedades do aspecto buscado como formato e orientação.

A componente externa ou potencial da energia tem como domínio a imagem e apresenta valores mínimos nas regiões de interesse. Tipicamente, as regiões de interesse são caracterizadas por grandes intensidades do vetor gradiente.

A componente externa da energia é usualmente referida por componente potencial. Ela é obtida pela integração de uma função energia potencial $\mathcal{P}(x(s), y(s))$ ao longo da curva $X(s)$. Matematicamente, a componente externa ou potencial da função energia é definida por

$$
P(X(s))=\int_{0}^{1} \mathcal{P}(X(s)) d s
$$

Das equações 2.1, 2.2 e 2.3, tem-se que a função energia pode ser definida mais explicitamente como

$$
\varepsilon(X)=\frac{1}{2} \int_{0}^{1}\left(\alpha(s)\left|\frac{\partial X}{\partial s}\right|^{2}+\beta(s)\left|\frac{\partial^{2} X}{\partial s^{2}}\right|^{2}+\mathcal{P}(X(s))\right) d s
$$

Matematicamente, o processo de conformação dos contornos deformáveis paramétricos segundo formulação por minimização da energia corresponde ao processo iterativo de minimização da função energia definida na equação 2.4 .

À medida em que a fundamentação teórica necessária à compreensão da dinâmica iterativa da curva e da condição de parada demanda amplas referências à teoria do cálculo variacional, julgou-se pela conveniência de dedicar no texto o subtópico seguinte (2.3.1) à sua elucidação. A definição e a solução do problema variacional básico foi incluída como forma de prover subsídios à definição da solução proposta. 


\subsubsection{Modelos Deformáveis à Luz do Cálculo Variacional}

A abordagem variacional tem sido proposta como solução de muitos problemas em pré-processamento de imagens [AMINI et al. (1990)]. Fluxos ópticos [LEE \& ANDERSON (2006), ROTH \& BLACK (2007)] e a detecção de bordas [MUMFORD \& SHAH (1988)] são exemplos bastante ilustrativos. Os modelos deformáveis, mais especificamente, foram concebidos como um problema variacional. Conforme proposto em KASS et al. (1988), os modelos deformáveis foram abordados originalmente como uma formulação geométrica lagrangeana na qual as bordas do modelo são representadas em forma paramétrica [MALLADI et al. (1995)].

O problema variacional básico consiste em determinar, pela busca no espaço de funções admissíveis, funções argumento $y(x)$ para as quais o funcional $J[y(x)]^{4}$ definido na equação 2.5, assume valores mínimos.

$$
\begin{array}{r}
J[y]=\int_{x_{0}}^{x_{1}} F\left(x, y, y^{\prime}\right), \\
x_{0}<x_{1}, \\
x, x_{0}, x_{1} \in \mathbb{R}
\end{array}
$$

Em notação matemática, o problema básico do cálculo variacional é definido como

$$
\text { s.a. }\left\{\begin{aligned}
\min & J[y] \\
y\left(x_{0}\right)=y_{o} & \\
y\left(x_{1}\right)=y_{1} &
\end{aligned}\right.
$$

Assim sendo, $y^{*}(x)$, uma função particular candidata a solução do problema, em obediência às restrições apresentadas em 2.8, deve ser tal que

\footnotetext{
${ }^{4}$ Escalar cujo valor depende de todo o curso de uma ou várias funções
} 


$$
\begin{aligned}
& y^{*}\left(x_{0}\right)=y_{0} \\
& y^{*}\left(x_{1}\right)=y_{1}
\end{aligned}
$$

A condição necessária à optimalidade advém de análise mais elaborada. As condições necessárias à ocorrência de um ponto extremo são representadas por um conjunto de equações diferenciais deduzidas originalmente por Euler mas, com vistas à sua implementação computacional, serão deduzidas aqui pela redução do problema variacional a um problema de cálculo diferencial. Será assumido, para isso, que todas as funções que ocorrerem na solução são diferenciáveis e que têm derivadas diferenciáveis ${ }^{5}$.

Diferentemente das funções, cujos valores são definidos pelo conhecimento de um ponto em um espaço de coordenadas, os funcionais assumem valores que dependem de todo o curso de uma ou várias funções. Assim sendo, uma pequena variação no argumento funcional $y(x)$ em uma vizinhança de $y^{*}(x)$ equivale à adição de um pequeno múltiplo de uma função bem comportada definida em todo o intervalo $\left[x_{0}, x_{1}\right]$ e não simplesmente à adição de um pequeno escalar.

Matematicamente, pelo uso do escalar $\epsilon$ suficientemente pequeno e da função $u(x):\left[x_{0}, x_{1}\right] \rightarrow \mathbb{R}, y(x)$ pode ser definida por

$$
y(x)=y^{*}(x)+\epsilon u(x)
$$

Disto decorre que, por diferenciação,

$$
y^{\prime}(x)=y^{*^{\prime}}(x)+\epsilon u^{\prime}(x)
$$

A Figura 2.1 ilustra a relação entre $y(x), y^{*}(x)$ e $u(x)$.

\footnotetext{
${ }^{5}$ Convém ressaltar que, quando observada a orientação à implementação computacional, esta assunção não constitui restrição prática
} 


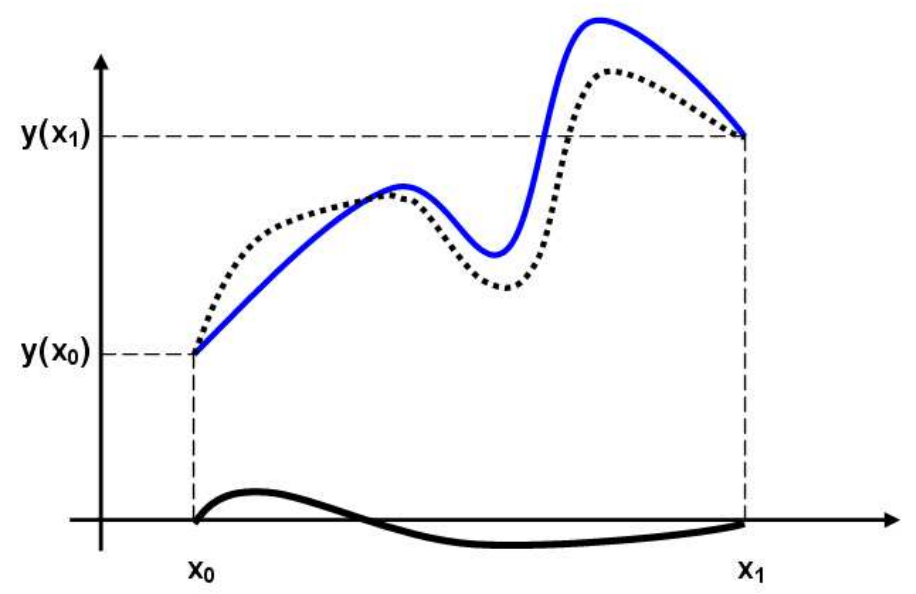

Figura 2.1: Relação entre $y(x)$ (azul), $y^{*}(x)$ (preto pontilhado) e $u(x)$ (preto sólido)

Logo, de 2.8 e 2.9 em 2.11 tem-se que a função $u(x)$ deve ser tal que

$$
u\left(x_{o}\right)=u\left(x_{1}\right)=0
$$

Por explicitação das relações apresentadas nas equações 2.11 e $2.12, F\left(x, y, y^{\prime}\right)$ pode, então, ser definida como

$$
F\left(x, y, y^{\prime}\right)=F\left(x, y^{*}(x)+\epsilon u(x), y^{*^{\prime}}(x)+\epsilon u^{\prime}(x)\right)
$$

$F\left(x, y, y^{\prime}\right)$ é definida pela expansão em série de Taylor de primeira ordem na vizinhança de $\left(x, y^{*}(x), y^{*^{\prime}}(x)\right)$ por

$$
F\left(x, y, y^{\prime}\right)=F\left(x, y^{*}(x), y^{*^{\prime}}(x)\right)+\left.\frac{\partial F}{\partial y}\right|_{y=y^{*}}(\epsilon u(x))+\left.\frac{\partial F}{\partial y^{\prime}}\right|_{y^{\prime}=y^{*^{\prime}}}\left(\epsilon u^{\prime}(x)\right)
$$

A variação no valor funcional $(\delta J[y])$ resultante da perturbação $\epsilon u(x)$ em seu argumento $y^{*}(x)$, é definida como 


$$
\delta J[y]=\int_{x_{o}}^{x_{1}} F\left(x, y^{*}(x)+\epsilon u(x), y^{*^{\prime}}(x)+\epsilon u^{\prime}(x)\right) d x-\int_{x_{o}}^{x_{1}} F\left(x, y^{*}(x), y^{*^{\prime}}\right)(x) d x
$$

Logo, de 2.14 e 2.15 em 2.16 tem-se que

$$
\delta J[y]=\epsilon \int_{x_{o}}^{x_{1}} \frac{\partial F}{\partial y}(u(x))+\frac{\partial F}{\partial y^{\prime}}\left(u^{\prime}(x)\right) d x
$$

Por integração por partes do segundo membro do integrando da equação 2.17 tem-se:

$$
\int_{x_{o}}^{x_{1}} \frac{\partial F}{\partial y^{\prime}}\left(u^{\prime}(x)\right) d x=\left.\frac{\partial F}{\partial y^{\prime}}(u(x))\right|_{x_{o}} ^{x_{1}}-\int_{x_{o}}^{x_{1}} u(x) \frac{d}{d x}\left(\frac{\partial F}{\partial y^{\prime}}\right) d x
$$

Como $u\left(x_{o}\right)=u\left(x_{1}\right)=0$, tem-se que

$$
\left.\frac{\partial F}{\partial y^{\prime}}(u(x))\right|_{x_{o}} ^{x_{1}}=0
$$

Portanto, de 2.19 em 2.18 obtém-se

$$
\int_{x_{o}}^{x_{1}} \frac{\partial F}{\partial y^{\prime}}\left(u^{\prime}(x)\right) d x=-\int_{x_{o}}^{x_{1}} u(x) \frac{d}{d x}\left(\frac{\partial F}{\partial y^{\prime}}\right) d x
$$

Que, em 2.17 resulta

$$
\delta J[y]=\int_{x_{o}}^{x_{1}}\left[\frac{\partial F}{\partial y}-\frac{d}{d x}\left(\frac{\partial F}{\partial y^{\prime}}\right)\right](\varepsilon u(x)) d x
$$

Como, em um ponto de mínimo, a repercussão da perturbação suficientemente pequena promovida no argumento do funcional deve ser nula, tem-se que, na solução do problema

$$
\delta J[y]=0
$$


De 2.22 em 2.21, portanto, obtém-se que a condição necessária pode ser enunciada por

$$
\int_{x_{o}}^{x_{1}}\left[\frac{\partial F}{\partial y}-\frac{d}{d x}\left(\frac{\partial F}{\partial y^{\prime}}\right)\right] \epsilon u(x) d x=0
$$

Seja, portanto, por fins de simplificação da notação, a substituição representada na equação 2.24 .

$$
f_{a}(x)=\left[\frac{\partial F}{\partial y}-\frac{d}{d x}\left(\frac{\partial F}{\partial y^{\prime}}\right)\right]
$$

Seja também, $u^{*}(x)$, uma função particular $u(x)$ suave tal que

$$
u^{*}(x)=\left\{\begin{array}{cc}
(x-\xi+\tau)^{2}(x-\xi-\tau)^{2}, & (\xi-\tau \leq x \leq \xi+\tau) \\
0, & \text { c.c. }
\end{array}\right.
$$

Caso haja $\xi \in\left[x_{o}, x_{1}\right]$ tal que $f_{a}(\xi) \neq 0$, pela continuidade de $f_{a}(x)$, deverá existir um intervalo $(\xi-\tau \leq x \leq \xi+\tau)$ no qual $f_{a}(x) \neq 0$. Disto decorre que a integral

$$
\int_{x_{0}}^{x_{1}} f_{a}(x) u^{*}(x) d x=\int_{\xi-\tau}^{\xi+\tau} f(x)(x-\xi+\tau)^{2}(x-\xi-\tau)^{2} d x
$$

que é diferente de zero. Assim, como $f_{a}(x) \neq 0$ e $u^{*}(x)>0$ em $(\xi-\tau, \xi+\tau)$, $f_{a}(x)$ é necessariamente zero. Disto decorre que $f_{a}(x)=0$ garante $\delta J[y]=0$ e, portano, tem-se que a equação 2.23 admite como única solução

$$
f_{a}(x)=0, x \in\left[x_{0}, x_{1}\right]
$$

De 2.27 em 2.24, portanto, tem-se que a condição necessária à optimalidade do problema variacional básico é

$$
\left[\frac{\partial F}{\partial y}-\frac{d}{d x}\left(\frac{\partial F}{\partial y^{\prime}}\right)\right]=0
$$


No caso específico dos contornos deformáveis, o problema de minimização da função 2.4 é formalizado como consta na equação 2.29.

$$
\text { s.a. }\left\{\begin{array}{l}
\min \\
X(0)=X(1)
\end{array} \varepsilon(X(s))=\int_{0}^{1} F\left(X(s), X^{\prime}(s), X^{\prime \prime}(s)\right) d s\right.
$$

Seja $\mathcal{X}(s)$ uma curva candidata a solução do problema. Por raciocínio idêntico ao descrito na abordagem ao problema básico, uma pequena variação no argumento do funcional pode ser obtida pela adição de um pequeno múltiplo de uma função bem comportada $u(s)$ tal que

$$
u(0)=u(1)=0
$$

Seja, portanto,

$$
X(s)=\mathcal{X}(s)+\epsilon u(s)
$$

com $\epsilon$ suficientemente pequeno. Disto decorre que

$$
\begin{array}{r}
X^{\prime}(s)=\mathcal{X}^{\prime}(s)+\epsilon u^{\prime}(s) \\
X^{\prime \prime}(s)=\mathcal{X}^{\prime \prime}(s)+\epsilon u^{\prime \prime}(s)
\end{array}
$$

Assim sendo, a variação do valor funcional $(\delta \varepsilon[X])$ resultante da perturbação $\epsilon u(s)$ em seu argumento em torno de $\mathcal{X}^{\prime}(s)$ é obtida por

$$
\begin{aligned}
\delta \varepsilon(X(s)= & \int_{0}^{1} F\left(\mathcal{X}(s)+\epsilon u(s), \mathcal{X}^{\prime}(s)+\epsilon u^{\prime}(s), \mathcal{X}^{\prime \prime}(s)+\epsilon u^{\prime \prime}(s)\right) d s \\
& -\int_{0}^{1} F\left(\mathcal{X}(s), \mathcal{X}^{\prime}(s), \mathcal{X}^{\prime \prime}(s)\right) d s
\end{aligned}
$$


Pela expansão de $F$ em série de Taylor de primeira ordem na vizinhança de $\left(\mathcal{X}(s), \mathcal{X}^{\prime}(s), \mathcal{X}^{\prime \prime}(s)\right)$ obtém-se

$$
\begin{gathered}
F\left(\mathcal{X}(s)+\epsilon u(s), \mathcal{X}^{\prime}(s)+\epsilon u^{\prime}(s), \mathcal{X}^{\prime \prime}(s)+\epsilon u^{\prime \prime}(s)\right)=F\left(X(s), X^{\prime}(s), X^{\prime \prime}(s)\right) \\
+\frac{\partial F}{\partial x}(\epsilon u(s))+\frac{\partial F}{\partial x^{\prime}}\left(\epsilon u^{\prime}(s)\right)+\frac{\partial F}{\partial x^{\prime \prime}}\left(\epsilon u^{\prime \prime}(s)\right)
\end{gathered}
$$

Logo, de 2.35 em 2.34 tem-se que a variação no valor funcional vale

$$
\delta \varepsilon[X(s)] \cong \int_{0}^{1} \frac{\partial F}{\partial X}(\epsilon u(s))+\frac{\partial F}{\partial X^{\prime}}\left(\epsilon u^{\prime}(s)\right)+\frac{\partial F}{\partial X^{\prime \prime}}\left(\epsilon u^{\prime \prime}(s)\right) d s
$$

Por integração por partes

$$
\int_{0}^{1} \frac{\partial F}{\partial X^{\prime}} \epsilon u^{\prime}(s) d s=\left.\frac{\partial F}{\partial X^{\prime}} \epsilon u(s)\right|_{0} ^{1}-\int_{0}^{1} \epsilon u(s) \frac{\partial}{\partial s}\left(\frac{\partial F}{\partial X^{\prime}} \epsilon u(s)\right) d s
$$

Portanto, de 2.30 em 2.37 obtém-se que

$$
\int_{0}^{1} \frac{\partial F}{\partial X^{\prime}} \epsilon u^{\prime}(s) d s=-\int_{0}^{1} \frac{\partial}{\partial s}\left(\frac{\partial F}{\partial X^{\prime}}\right) \epsilon u(s) d s
$$

Em procedimento idêntico,

$$
\int_{0}^{1} \frac{\partial F}{\partial X^{\prime \prime}}\left(\varepsilon u^{\prime \prime}(x)\right)=\left.\frac{\partial F}{\partial X^{\prime \prime}} \varepsilon u^{\prime}(s)\right|_{0} ^{1}-\int_{0}^{1} \varepsilon u^{\prime}(s) \frac{\partial}{\partial s}\left(\frac{\partial F}{\partial X^{\prime \prime}}\right) d s
$$

Logo, 


$$
\begin{aligned}
\int_{0}^{1} \frac{\partial F}{\partial X^{\prime \prime}}\left(\epsilon u^{\prime \prime}(x)\right) d s= & \left.\frac{\partial F}{\partial X^{\prime \prime}} \epsilon u^{\prime}(s)\right|_{0} ^{1}-\left[\left.\frac{\partial}{\partial s}\left(\frac{\partial F}{\partial X^{\prime \prime}}\right) \epsilon u(s)\right|_{0} ^{1}\right. \\
& \left.-\int_{0}^{1} \epsilon u(s) \frac{\partial^{2}}{\partial s^{2}}\left(\frac{\partial F}{\partial X^{\prime \prime}}\right) d s\right]
\end{aligned}
$$

Mais uma vez, por evocação de 2.30 tem-se que

$$
\left.\frac{\partial}{\partial s}\left(\frac{\partial F}{\partial X^{\prime \prime}}\right) \epsilon u(s)\right|_{0} ^{1}=0
$$

Uma vez que o conorno é fechado

$$
\left.\frac{\partial F}{\partial X^{\prime \prime}}\right|_{s=0}=\left.\frac{\partial F}{\partial X^{\prime \prime}}\right|_{s=1}
$$

e,

$$
u^{\prime}(0)=u^{\prime}(1)
$$

Logo,

$$
\left.\frac{\partial F}{\partial X^{\prime \prime}} \epsilon u(s)^{\prime}\right|_{0} ^{1}=0
$$

Portanto, de 2.39 e 2.44 em 2.38 obtém-se

$$
\int_{0}^{1} \frac{\partial F}{\partial X^{\prime \prime}}\left(\epsilon u^{\prime \prime}(s)\right) d s=\int_{0}^{1} \epsilon u(s) \frac{\partial^{2}}{\partial s^{2}}\left(\frac{\partial F}{\partial X^{\prime \prime}}\right) d s
$$

Finalmente, de 2.38 e 2.45 em 2.36, tem-se que

$$
\delta \epsilon[X(s)]=\int_{x_{o}}^{x_{1}}\left[\frac{\partial F}{\partial X}-\frac{\partial}{\partial s}\left(\frac{\partial F}{\partial X^{\prime}}\right)+\frac{\partial^{2}}{\partial s^{2}} \frac{\partial F}{\partial X^{\prime \prime}}\right](\varepsilon u(s)) d s
$$

Como, em um ponto de mínimo $\delta \varepsilon[X(s)]=0$, por uso do raciocínio descrito nas equações 2.21 a 2.25 obtém-se que 


$$
\frac{\partial F}{\partial X}-\frac{\partial}{\partial s}\left(\frac{\partial F}{\partial X^{\prime}}\right)+\frac{\partial^{2}}{\partial s^{2}} \frac{\partial F}{\partial X^{\prime \prime}}=0
$$

Como

$$
\begin{aligned}
\frac{\partial F}{\partial X} & =\nabla \mathcal{P}(x) \\
\frac{\partial}{\partial s}\left(\frac{\partial F}{\partial X^{\prime}}\right) & =\frac{\partial}{\partial s}\left(\alpha \frac{\partial F}{\partial X^{\prime}}\right) \\
\frac{\partial^{2}}{\partial s^{2}}\left(\frac{\partial F}{\partial X^{\prime \prime}}\right) & =\frac{\partial^{2}}{\partial s^{2}}\left(\beta \frac{\partial^{2} F}{\partial s}\right)
\end{aligned}
$$

Obtém-se como condição necessária à optimalidade que

$$
\frac{\partial}{\partial s}\left(\alpha \frac{\partial X}{\partial s}\right)-\frac{\partial^{2}}{\partial s^{2}}\left(\beta \frac{\partial^{2} X}{\partial s^{2}}\right)-\nabla \mathcal{P}(X)=0
$$

De modo a de prover algum nível de plausibilidade física é comum definir a formulação dinâmica dos contornos deformáveis por uso do seguinte modelo cinemático animado pela ação de forças internas $F_{\text {int }}$ e forças externas $F_{\text {ext }}$ conforme consta na equação 2.52

$$
\mu \frac{\partial^{2} X}{\partial t^{2}}=-\gamma \frac{\partial X}{\partial t}+F_{\text {int }}(X)+F_{\text {ext }}(X)
$$

na qual os termos $\mu$ e $\gamma$ correspondem à massa e ao coeficiente de atrito viscoso, respectivamente.

Usualmente é assumido que as partículas têm massa desprezível. Disto decorre que o sistema da equação 2.52 passa a corresponder a um sistema físico super amortecido com equação de movimento definida por

$$
\gamma \frac{\partial X}{\partial t}=F_{\text {int }}(X)+F_{\text {ext }}(X)
$$

no qual 


$$
F_{\text {int }}(X)=\frac{\partial}{\partial s}\left(\alpha \frac{\partial X}{\partial s}\right)-\frac{\partial^{2}}{\partial s^{2}}\left(\beta \frac{\partial^{2} X}{\partial s^{2}}\right)
$$

$\mathrm{e}$

$$
F_{\text {ext }}(X)=F_{\text {pot }}(X)=-\nabla \mathcal{P}(X)
$$

É usual dissossiar a componente interna das forças em duas parcelas denominadas força de tensão $F_{t}$ e força de curvatura $F_{c}$ de modo que

$$
F_{\text {int }}(X)=F_{t}(X)+F_{c}(X)
$$

sendo que

$$
F_{t}(X)=\frac{\partial}{\partial s}\left(\alpha \frac{\partial X}{\partial s}\right)
$$

e

$$
F_{c}(X)=-\frac{\partial^{2}}{\partial s^{2}}\left(\beta \frac{\partial^{2} X}{\partial s^{2}}\right)
$$

A equação 2.56, portanto, pode ser reescrita como

$$
F_{\text {int }}(X)+F_{\text {pot }}(X)=0
$$

que corresponde a condição de parada do processo evolutivo.

A evolução do contorno deformável, então, é obtida por processo iterativo cuja dinâmica corresponde à evolução de um sistema mecânico para o equilíbrio e cujas velocidades dos pontos constituintes é definida conforme consta na equação 2.60 .

$$
\gamma \frac{\partial X}{\partial t}=\frac{\partial}{\partial s}\left(\alpha \frac{\partial X}{\partial s}\right)-\frac{\partial^{2}}{\partial s^{2}}\left(\beta \frac{\partial^{2} X}{\partial s^{2}}\right)-\nabla \mathcal{P}(X)
$$




\subsection{Formulação Dinâmica}

Na formulação paramétrica dos modelos deformáveis a força externa é a única responsável por guiar o contorno para as regiões de interesse. Na formulação paramétrica por minimização da energia, mais especificamente, esta tendência é incorporada no modelo pela definição de uma componente da função energia que apresenta mínimos nas regiões buscadas. Nesta formulação, a componente externa da força corresponde ao oposto do gradiente da função potencial energia e, por consequência, os campos de força externa são necessariamente conservativos.

Na formulação dinâmica a força externa resultante sobre cada ponto do contorno deformável atua de modo a conduzí-lo para as regiões de interesse mas, diferentemente do que ocorre na formulação por minimização da energia, não se associa necessariamente à minimização de uma função energia potencial. A formulação dinâmica dos modelos deformáveis é uma formulação mais geral e permite a incorporação de componentes de força externa mais abrangentes. Esta flexibilidade permite, em tese, a definição de campos de melhor qualidade.

A evolução dos contornos deformáveis segundo a formulação dinâmica também ocorre em obediência à equação 2.52. Como única diferença consta o fato de que a força externa é definida pela contribuição de variadas forças (não necessariamente conservativas), conforme enuncia a equação 2.61 .

$$
F_{\text {ext }}(X)=\sum_{i=1}^{n} F_{i}(X)
$$

Variados modelos de força têm sido investigados e alguns deles têm sido reconhecidos como contribuições expressivas na área.

\subsection{Forças Externas}

A menos das formulações diferentes [YUNG (1997), WERUAGA et al. (2004)], a abordagem às limitações dos contornos deformáveis tem se dado pela busca de 
modelos de força externa de melhor qualidade. Os tópicos subsequentes serão dedicados à descrição das contribuições mais expressivas.

\subsection{Força Potencial Gaussiana}

O primeiro modelo de força externa utilizado nos contornos deformáveis foi a força potencial gaussiana [KASS et al. (1988)]. A força gaussiana é definida em termos de uma energia potencial denominada energia potencial gaussiana. Esse modelo de força constitui uma solução rudimentar para a condução do contorno para as regiões de interesse.

A força potencial gaussiana demanda pequeno esforço computacional e é de fácil implementação mas, como desvantagem, conjuga deficientemente as propriedades abrangência espacial e fidelidade. Matematicamente a energia potencial gaussiana é definida por

$$
P(x, y)=-w_{e}\left|\nabla\left[G_{\sigma}(\bar{x}, \bar{y}) * \Gamma(x, y)\right]\right|^{2}
$$

na qual $w_{e}$ é um parâmetro positivo de peso, $\nabla$ é o operador gradiente, * é o operador convolução bidimensional, $\Gamma(x, y)$ é o sinal e $G_{\sigma}(\bar{x}, \bar{y})$ é uma função gaussiana bidimensional de desvio padrão $\sigma$ definida por

$$
G_{\sigma}(\bar{x}, \bar{y})=\frac{1}{2 \pi \sigma} e^{-\frac{(x-\bar{x})^{2}+(y-\bar{y})^{2}}{\sigma^{2}}}
$$

A Figura 2.2 apresenta exemplos de funções gaussianas com parâmetros variados. 
(a)

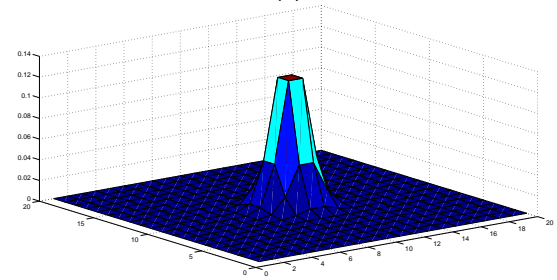

(c)

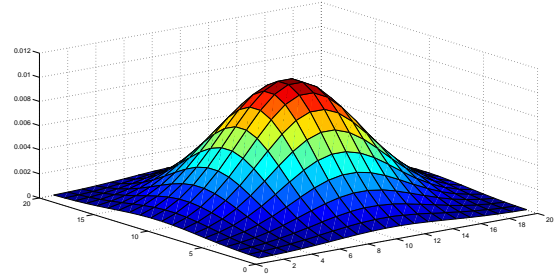

(b)

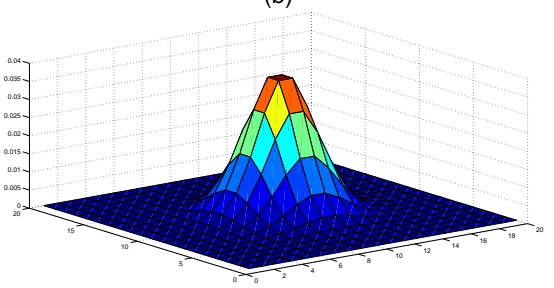

(d)

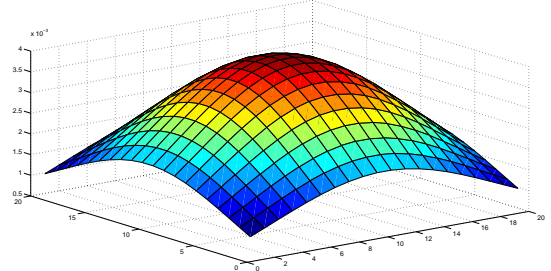

Figura 2.2: Máscaras de convolução gaussianas de dimensão 20 x 20 e desvios padrões: $\sigma=1$ (a), $\sigma=2$ (b), $\sigma=4$ (c) e $\sigma=8$ (d)

Seja, por exemplo, a imagem sintética complexa apresentada na Figura 2.3,

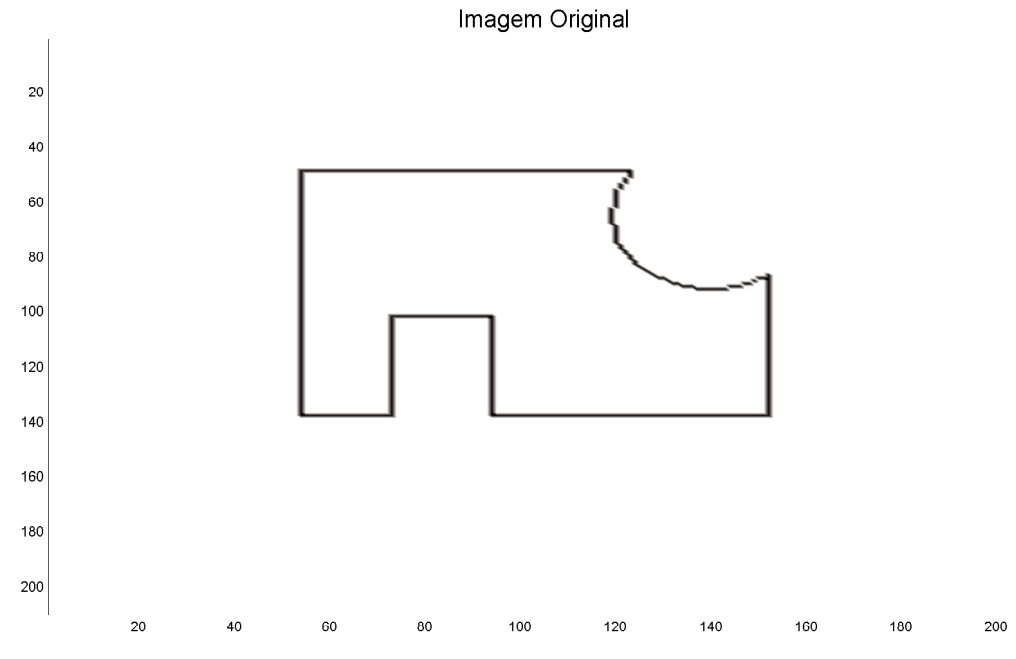

Figura 2.3: Imagem sintética complexa (SC)

As Figuras 2.4 a, b, c e d apresentam a intensidade da energia potencial gaussiana obtida por uso das máscaras de convolução apresentadas nas Figuras $2.2 \mathrm{a}, \mathrm{b}, \mathrm{c}$ e d, respectivamente. 
(b)

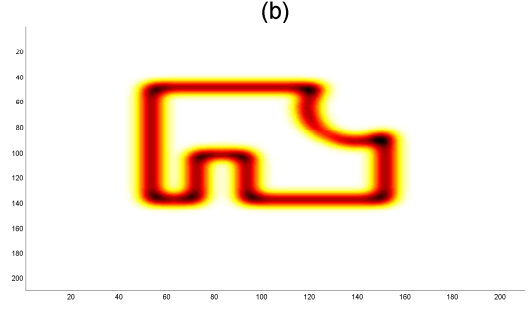

(c)

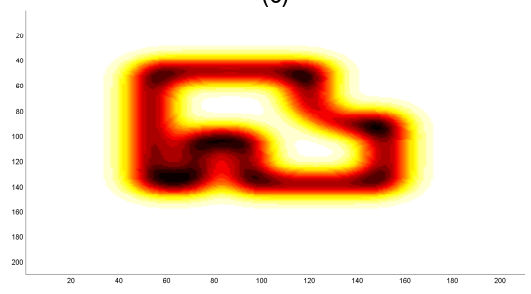

(c)

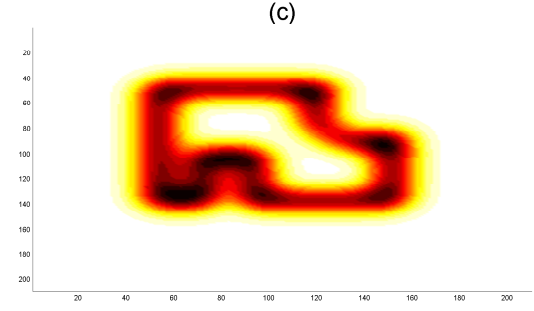

(d)

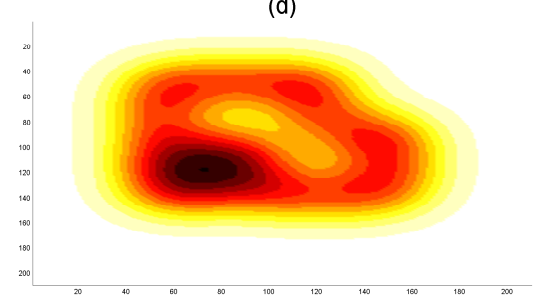

Figura 2.4: Função potencial de energia gaussiana obtida da imagem da Figura 2.3 pelo uso das máscaras de convolução na Figura 2.2

A Figura 2.5 apresenta a intensidade do campo de forças obtido a partir da energia apresentada na Figura 2.4 (b).

(b)

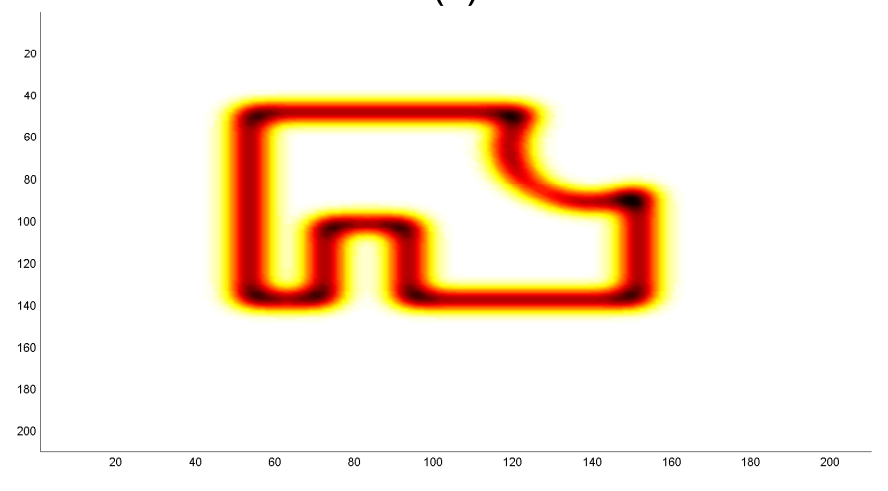

Figura 2.5: Campo de forças potencial gaussiana obtidas da imagem 2.3 por convolução com máscaras gaussianas de desvios padrão $\sigma=16$ e dimensão 20x20

A Figura 2.6 ilustra os contornos obtidos por uso das máscaras de convolução de variados parâmetros. 

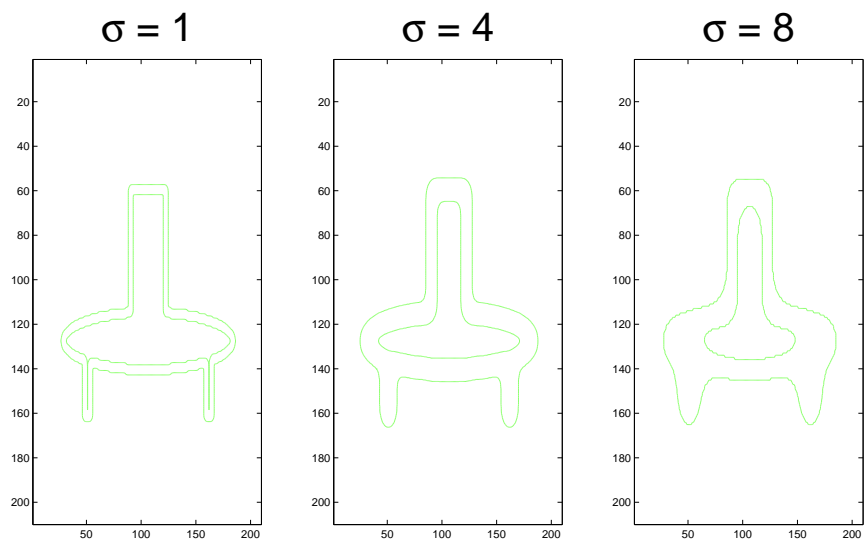

Figura 2.6: Curvas de nível da intensidade da força potencial gaussiana obtida por máscaras gaussianas de variados desvios padrão

\subsection{Força Potencial Gaussiana Multi Escala}

A utilização da força gaussiana conforme apresentada na seção 2.6 impõe relação de compromisso tácito entre a abrangência da força externa e a sua capacidade de aproximar com fidelidade o contorno buscado. Conforme ilustram as Figuras 2.6 a, b e c, as maiores abrangências da força externa só são obtidas na força gaussiana ao custo da diminuição da fidelidade da identificação.

O termo $G_{\sigma}(\bar{x}, \bar{y}) * \Gamma(x, y)$ da equação 2.62 corresponde à filtragem passa baixas da imagem e, portanto, define uma versão suavizada da imagem original $\Gamma(x, y)$. Disto decorre que o uso de funções gaussianas com maiores valores de desvio padrão, ao implicar em restrições mais severas no espectro de frequências da imagem, é responsável pelo arredondamento do contorno identificado. O uso das forças potenciais gaussianas define um dilema de difícil solução.

Em [TERZOPOULOS et al. (1988)] Terzopoulos, Kass e Witkin propuseram uma metodologia mais elaborada que aborda eficientemente esta questão. Conhecida como força potencial gaussiana multi escala, a proposta consiste na obtenção de funções energias potenciais gaussianas pelo uso de diferentes valores de desvio padrão. Consegue-se, desta forma, através do espaço de escalas obtido, aliar o 
aumento da abrangência da força (obtido pela utilização de valores mais altos de desvio padrão) à fidelidade da identificação (obtida pelo uso dos menores valores de $\sigma)$.

Metodologicamente, a idéia básica é primeiro utilizar os maiores valores de $\sigma$ para definir grandes vales na energia potencial em torno dos contornos buscados e, à medida em que o contorno evolue, promover diminuição gradual nos valores do desvio padrão de modo a obter escalas mais finas e fiéis.

A principal contribuição da força potencial gaussiana multi escala foi a substancial extensão da abrangência das forças externas, uma questão crítica por aquela ocasição. A força potencial gaussiana multi escala permite que sejam utilizados inicialmente os espacialmente vastos campos de força obtidos para as escalas menos resolutas na inicialização do contorno e, ao mesmo tempo, torna possível a obtenção de contornos mais fiéis à medida em que são utilizados campos de força mais ricos em escalas mais resolutas.

\subsection{Força Distância}

A força potencial gaussiana multi escala proposta em COHEN et al. (1993) foi expressiva no que tange à extenção da abrangência espacial dos contornos deformáveis. A contribuição lançou luz à aplicabilidade dos contornos deformáveis em sistemas automáticos de detecção, entretanto, a efetividade de sua implementação é limitada por uma questão relevante. Não se dispõe de ferramentas analíticas que possam ser utilizadas na definição ótima dos decrementos do desvio padrão da função gaussiana $G_{\sigma}(\bar{x}, \bar{y})$ e, em agravamento ao problema, consta o fato de que a adoção de diferentes estratégias de variação do desvio padrão implica na obtenção de resultados substancialmente diferentes.

Cohen apresentou contribuição que aborda eficientemente esta questão, a força distância. O modelo de força externa proposto é definido por um campo de forças conservativo obtido a partir de uma função de energia potencial denominada energia potencial distância. A energia potencial, por sua vez, é função de um 
mapa de distâncias $d(\bar{x}, \bar{y})$ definido sobre a imagem $\Gamma(x, y)$.

O mapa de distâncias $d(\bar{x}, \bar{y})$ consiste de um espaço em $R^{2}$ com o mesmo tamanho da imagem original. Cada ponto do mapa tem valor igual à menor distância euclidiana entre o pixel correspondente na imagem e um ponto de borda. Matematicamente o mapa distância é definido por

$$
\begin{aligned}
& d(\bar{x}, \bar{y})=\quad \min \quad\|(x-\bar{x}, y-\bar{y})\| \\
& \text { s.a. }\left\{\begin{array}{l}
\Gamma(x, y) \in B_{\Gamma} \\
\text { x e y pertencem à imagem }
\end{array}\right.
\end{aligned}
$$

A Figura 2.8 ilustra o mapa de distância obtido para a imagem sintética complexa SC-5.

(a)

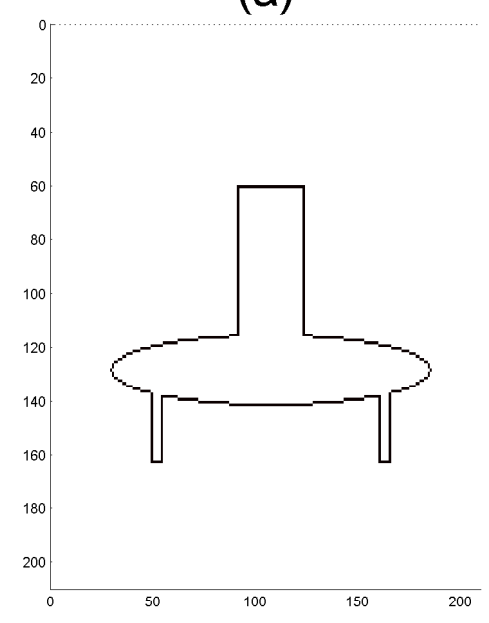

(b)

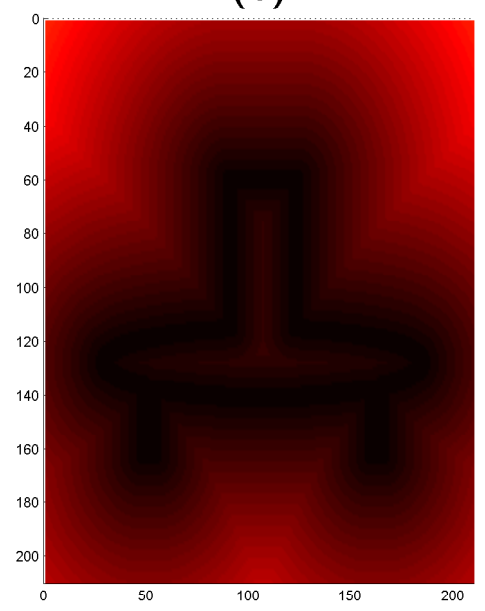

Figura 2.7: Imagem sintética complexa SC-5 e o mapa de distâncias associado

A função potencial distância tem como argumento o mapa de distâncias e é definida como na equação 2.65

$$
P_{d}(x, y)=-w_{d} e^{\left[-d(x, y)^{2}\right]}
$$

na qual $w_{d}$ representa uma constante multiplicativa constante denominada peso. 
A força potencial distância propriamente dita é definida como na equação 2.66

$$
f_{d}(x, y)=\nabla\left(w_{d} e^{\left[-d(x, y)^{2}\right]}\right)
$$

A Figura 2.8 apresenta o campo de forças correspondente ao mapa de distâncias apresentado na Figura 2.8

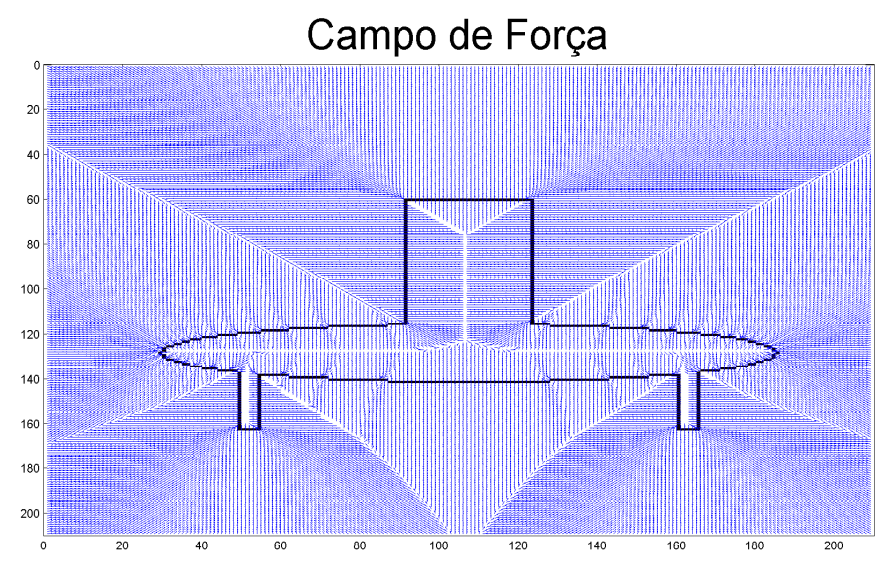

Figura 2.8: Campo de forças distância

A força potencial distância extendeu a aplicabilidade da técnica ao trato de imagens com objetos mais complexos e, por consequência, requisitos mais severos foram definidos.

\subsection{Força Distância Dinâmica}

A força distância proposta em COHEN et al. (1993) representou avanço expressivo na área dos contornos deformáveis. Esse modelo de força apresenta abrangência espacial que supera em muito a força potencial gaussiana e, em acréscimo, não apresenta a inconveniente influência de parâmetros sintonizáveis sobre o equilíbrio do sistema.

A força potencial distância proposta por Cohen definiu solução para o problema imposto pela força potencial gaussiana e foi provedora de grande abrangência espacial do campo de força. Entretanto, esse modelo de força apresentava como 
grande demérito sua incapacidade de tratar imagens com concavidades acentuadas.

Sejam, por exemplo, a imagem sintética SC-2 e o seu detalhe ilustrado nas Figuras 2.6 a e b. É perceptível que nas regiões côncavas o campo de força distância apresenta direções que tendem a guiar o contorno para a borda mais próxima. Ao fazê-lo, a força distância define em regiões côncavas um campo de forças que não força o contorno a avançar nas concavidades. A força potencial distância dinâmica [MACDONALD et al. (1994)], apresenta a boa abrangência espacial da força distância mas, diferentemente de sua predecessora, não apresenta a incapacidade de aproximar as concavidades. A metodologia proposta por Cohen, denominada força potencial distância dinâmica consiste na definição da força externa em cada ponto do contorno pelo cálculo da distância orientada na direção normal ao contorno.

A distância com sinal é calculada pela definição do pixel de interesse à menor distância na direção normal ao modelo. Esta distância é calculada a cada iteração do modelo. A força potencial distância dinâmica pode atrair o contorno deformável para aspectos da imagem extremamente distantes.

Dado um ponto $X$ na superfície do contorno, seu vetor normal $\vec{N}(X)$, a distância calculada $D(X)$ e um limite para a distância máxima $D_{\max }$, a força dinâmica é definida como na equação 2.67 .

$$
\vec{F}_{D}(X)=w_{D} \frac{D(X)}{D_{\max }} \vec{N}(X)
$$

na qual $w_{D}$ assume um valor constante correspondente ao peso.

\subsection{Força Balão}

A busca linear promovida a cada iteração e em cada ponto do contorno na força distância é processo dispendioso do ponto de vista computacional e torna o método de cálculo lento. O problema é abordado por meio da definição de menores 
distâncias máxima da busca o que, em contrapartida, reduz a abrangência da força.

Em [COHEN et al. (1993)] registrou-se progresso expressivo no trato das limitações dos contornos deformáveis quanto à abrangência da força externa e ao seu colapso. Pela definição de um modelo de força externa que ele denominou balão, Cohen apresentou técnica que aborda eficientemente a limitada abrangência espacial das forças externas e a tendência do contorno ao colapso imposta pela componente de tensão da força interna. Em verdade, a proposta de Cohen consiste de uma metodologia constituída por duas etapas fundamentais: normalização da força externa e aplicação da força balão.

Os modelos tradicionais de força externa são mais intensos nas regiões próximas aos contornos de interesse e, consequentemente, apresentam menores intensidades nas regiões mais afastadas. Disto decorre que a evolução do contorno deformável tende a ser mais lenta em regiões mais afastadas. A questão costuma ser abordada na implementação computacional do método pela utilização de incrementos de tempo $(\Delta t)$ variáveis. A abordagem típica ao problema consiste em utilizar maiores valores de $\Delta t$ para pontos distantes e menores valores de $\Delta t$ para pontos mais próximos do contorno buscado. A atualização ótima do incremento é um problema de difícil solução.

A normalização proposta por Cohen consiste em, ao invés de se variar o passo $\Delta t$, uniformizar a intensidade das forças externas. Diferentemente da simples definição de uma força externa como consta na equação 2.13, Cohen propôs a uniformização da sua intensidade. Conforme ilustra a equação 2.68, o campo de força normalizado consiste de um campo de intensidade constante $k$.

$$
\Delta F_{p o t}=-k \frac{\nabla P}{\|\nabla P\|}
$$

Essa convergência simula a definição de passos $\Delta t$ variáveis e convenientes aos variados graus evolutivos dos contornos deformáveis. As Figuras 2.10 b e c ilustram um campo de forças externas distância antes e após a uniformização. 
(a)

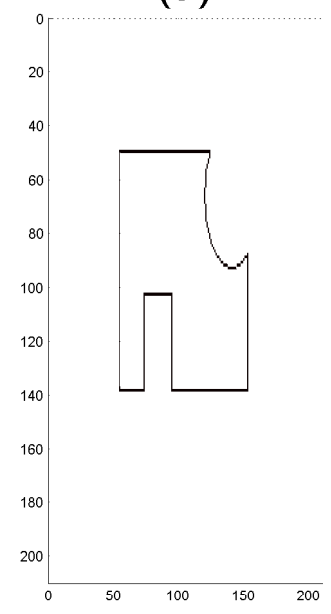

(b)

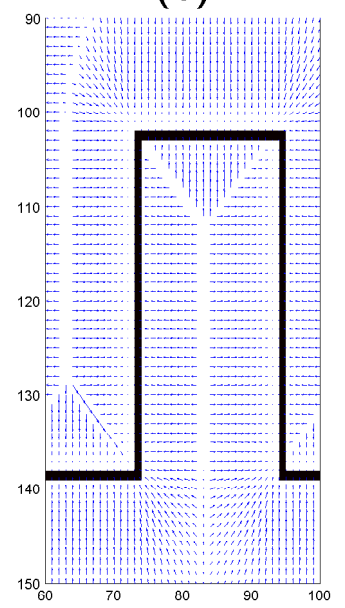

(c)

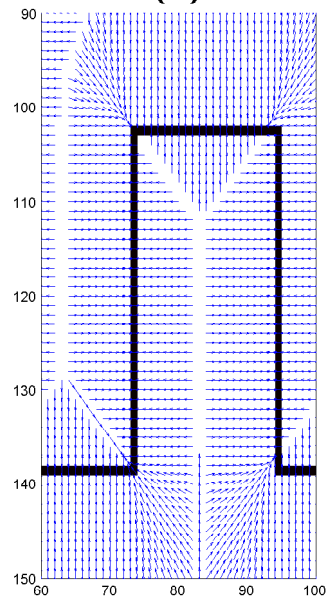

Figura 2.9: Contorno (a) e campos de força distância original (b) e normalizado (c) em concavidade

A segunda etapa da solução proposta, a definição propriamente dita das forças balão, trata diretamente de uma questão referente à evolução dos contornos deformáveis. Quando a componente de força externa é desprezível a minimização de sua função energia se dá pela aproximação de seus pontos. Com efeito, a snake entra em colapso. A contribuição de Cohen acessou o problema pela definição de uma componente de força interna que contraria esta tendência e tende a inflar a snake. Esse é o motivo pelo qual ela é referida como força balão.

A força balão é definida por

$$
F_{b a l}=k_{1} \vec{n}(s)
$$

na qual a constante $k_{1}$ define a amplitude da força balão e $\vec{n}(s)$ corresponde ao vetor normal à curva.

Conjuntamente, resultante da etapa de normalização da força externa e da ação da força balão a força externa pode ser definida por

$$
F_{p o t}=k_{1} \vec{n}(s)+k \frac{\nabla P}{\|\nabla P\|}
$$


Como contribuições de Cohen destacam-se a definição de modelos mais abrangentes de força externa e a tendência maior à evolução do contorno mesmo quando sobre fraca influência das regiões de interesse.

Como desvantagem da metodologia consta a necessidade de inicializar a força quanto à expansão ou contração e a intolerância aos contornos pouco definidos.

\subsection{Gradient Vector Flow}

Em [XU \& PRINCE (1998)] foi proposto um modelo de força externa que apresenta grande abrangência espacial e grande capacidade de atrair o contorno para as concavidades. O gradient vector flow conjuga as melhores características dos modelos anteriores e aborda eficientemente suas limitações.

Diferentemente das forças balão, a $G V F$ não necessita ser inicializada quanto a inflar ou encolher, tem uma maior faixa de captura e permite por consequência a inicialização do contorno mais distante do contorno buscado. O modelo de força externa que apresenta abrangência equivalente à GVF é a força externa potencial distância, entretanto, diferetemente desta, o GVF apresenta bons resultados na evolução do contorno para as regiões côncavas. A GVF também é invariante no tempo e independente do contorno deformável.

O princípio do modelo de força externa proposto por Xie e Prince é manter a propriedade desejável do gradiente nas regiões próximas às bordas (são normais às bordas e intensos) e utilizar o processo de difusão para extender o campo de força externa em regiões homogêneas.

Matematicamente, o campo $\operatorname{GVF} U V(x, y)=[u(x, y), v(x, y)]$ é obtido em solução a

$$
\min \iint \mu\left(\frac{\partial u^{2}}{\partial x}+\frac{\partial u^{2}}{\partial y}+{\frac{\partial v^{2}}{\partial x}}^{2} \frac{\partial v^{2}}{\partial y}\right)+\left|\nabla B_{\Gamma}\right|^{2}\left|U V-\nabla B_{\Gamma}\right|^{2} d x d y
$$


Essa formulação variacional segue o princípio padrão de manter o resultado suave quando não há dado. Em particular, pode-se perceber que quando $\left|\nabla B_{\Gamma}\right|$ é pequeno, a energia é dominada pela soma das energias das componentes de derivadas parciais das funções de energia. Por outro lado, quando $\left|\nabla B_{\Gamma}\right|$ é grande, o segundo termo domina a integral que é minimizada por fazer $U V=\nabla B_{\Gamma}$. Isto produz o efeito desejado de manter $U V$ aproximadamente igual ao mapa de bordas quando esse é intenso, mas torna pequenas variações em regiões homogeneas. O parametro $\mu$ regula a taxa entre o primeiro e o segundo termo da integração ${ }^{6}$. Esse termo deve ser definido em função da intensidade do ruído na imagem.

Nota-se que o termo de suavização $\mu$ corresponde a uma penalidade igual tanto para a componente divergente e rotacional do campo, logo, o campo resultante da minimização não pode ser inteiramente irrotacional ou nao solenoidal.

Usando o cálculo variacional pode ser mostrado que o GVF pode ser determinado pela solução das equações

$$
\begin{aligned}
& \mu \nabla^{2} u-\left(u-B_{\Gamma x}\right)\left(B_{\Gamma_{x}}^{2}+B_{\Gamma_{y}}^{2}\right)=0 \\
& \mu \nabla^{2} v-\left(v-B_{\Gamma y}\right)\left(B_{\Gamma_{x}}^{2}+B_{\Gamma_{y}}^{2}\right)=0
\end{aligned}
$$

na qual $\nabla^{2}$ é o operador laplaciano.

\footnotetext{
${ }^{6}$ diferentemente do que ocorrera na equação 2.52 , o parâmetro $\mu$, aqui, conforme definido pelo autor, não é análogo à massa
} 


\section{Capítulo 3}

\section{Solução Proposta}

A concepção de novos modelos de força externa tem sido a essência das investigações orientadas à melhoria dos aspectos funcionais dos contornos deformáveis paramétricos. Modelos inéditos de força têm abordado eficientemente questões relevantes. Dispõe-se hoje de forças externas de qualidade que superam em muito a original força potencial gaussiana. O GVF, por exemplo, tem sido reconhecida como força de excelente qualidade e dominado as aplicações dos contornos deformáveis.

A despeito da evolução expressiva na área dos contornos deformáveis, a técnica ainda apresenta problemas flagrantes. Ainda que sob a ação de campos vetoriais de força externa de boa qualidade, pontos do contorno deformável eventualmente estacionam em mínimos locais, em pontos demasiadamente próximos ou em pontos desgarrados do contorno de interesse. A Figura 3.1, por exemplo, ilustra a evolução de um contorno deformável sob a ação do campo de força GVF para uma imagem sintética muito bem definida.

Propriedades intrínsecas à formulação proposta por Kass contrariam a tendência do modelo deformável de evoluir para o contorno buscado. A atenção estrita à minimização da função energia definida em KASS et al. (1988) não contempla eventuais adensamentos ou esparsamentos indesejados de pontos. Com efeito, a formulação original dos contornos deformáveis não contempla a análise das 


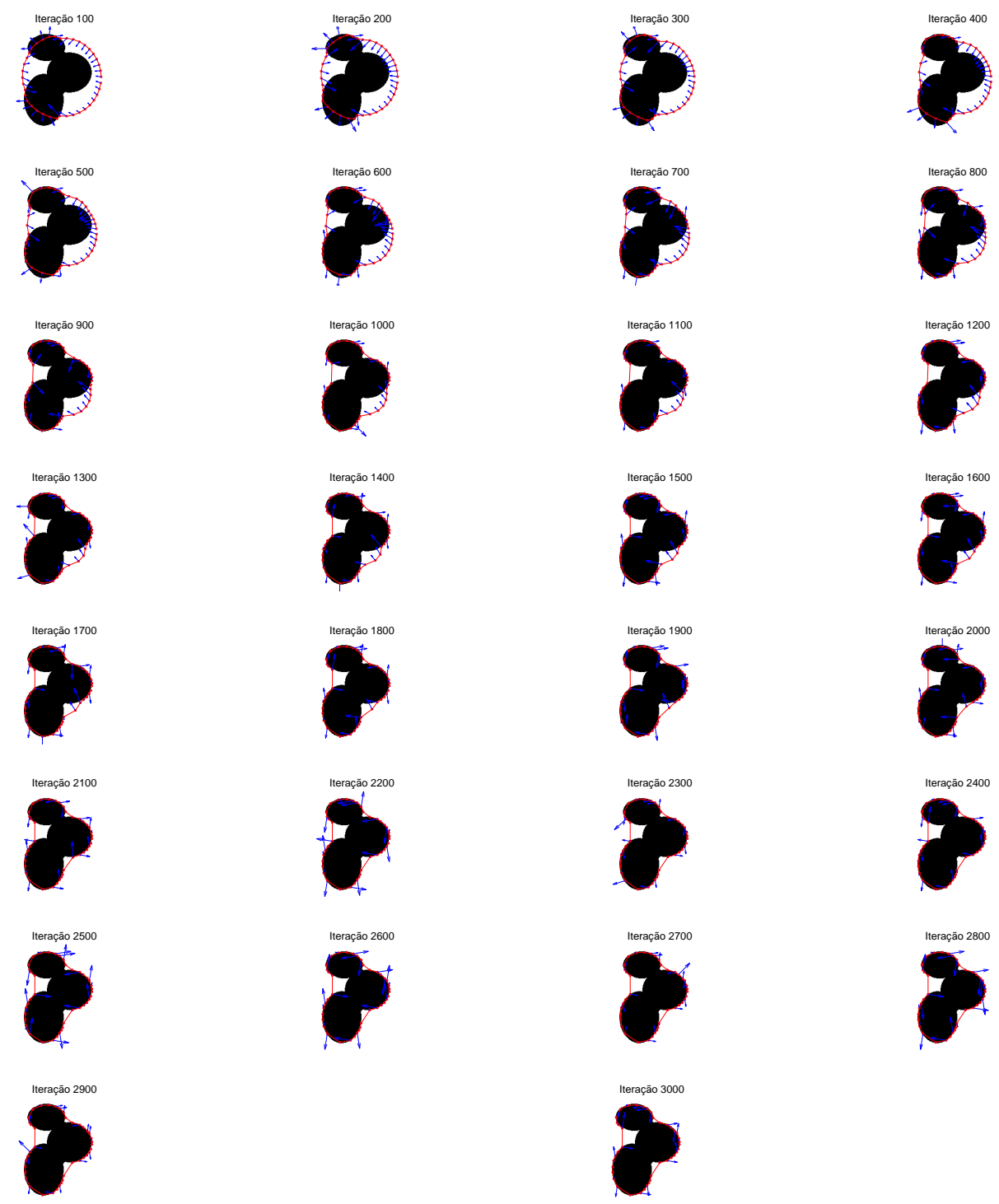

Figura 3.1: Evolução de contorno deformável sob ação de força GVF

distâncias ótimas entre seus pontos e é insensível à eventual inadequação de pontos espúrios ao contorno buscado. Desse modo, o contorno deformável evolui com a possibilidade de desprivilegiar regiões do contorno ao custo de expressiva diminuição da fidelidade global do contorno identificado.

Excepcionalmente no caso dos contornos deformáveis leves (constituídos por poucos pontos), esta desatenção ao posicionamento dos pontos ao longo do contorno implica em perdas apreciáveis da fidelidade na representação dos objetos de interesse. Os contornos deformáveis tornam-se, portanto, inadequados à aplicação na detecção de contornos com grandes concavidades com grandes concavidades 
e geometrias complexas ou o fazem a custo da apreciável elevação no número de pontos constituintes.

Seja, por exemplo, a evolução descrita na Figura 3.2. Conforme as trajetórias dos pontos evidenciam, apesar de os pontos serem iniciados equidistantes, a sua evolução sob ação das forças internas e da GVF impõe adensamentos em regiões que, do ponto de vista global, importam na incapacidade do contorno aproximar outras regiões do contorno buscado.
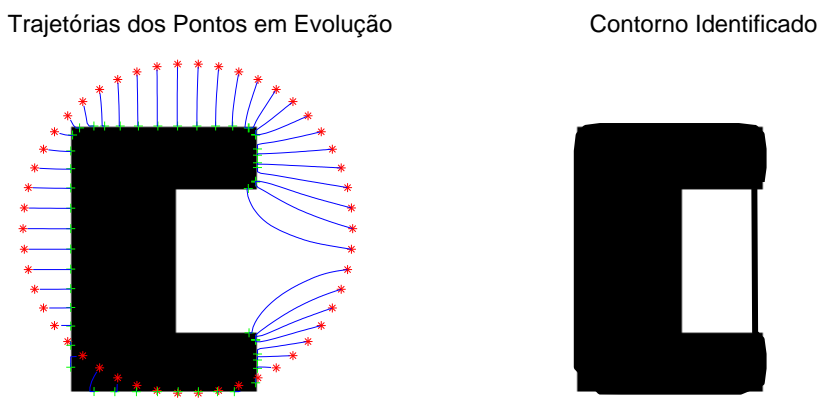

Figura 3.2: Trajetória descritas pelos pontos do contorno deformável em sua evolução sob ação exclusiva das forças internas e externas: $\left(^{*}\right)$ pontos conforme iniciados, (-) suas trajetórias e (+) suas posições ao término das iterações

Em outras palavras, conforme consta no detalhe apresentado na Figura 3.3, a animação dos pontos do contorno de modo a minimizar a função energia definida em KASS et al. (1988) não assegura a melhor representação do contorno buscado por uso dos pontos disponíveis. 


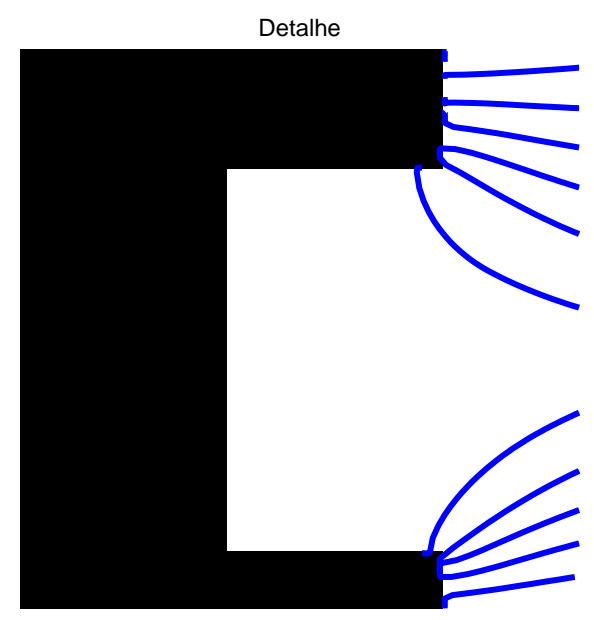

Figura 3.3: Detalhe da trajetória descrita pelos pontos do contorno deformável em sua evolução sob ação exclusiva das forças internas e externas: (-) trajetória dos pontos ao longo das iterações

Este trabalho propõe um modelo inédito de força. Denominada força de corrugação, o modelo proposto tem como domínio o contorno mas, diferentemente das forças internas, seu princípio particularmente inovador é atuar sobre os pontos do contorno de modo a reposicioná-los sobre a curva original. Em primeira análise, portanto, a força de corrugação não guia os pontos às regiões de interesse. A sua ação na evolução do contorno potencializa a ação das forças externas nesse intento.

Mais especificamente, a solução apresentada consiste na definição de uma nova natureza de força que define atitudes do contorno complementares às associadas ao processo de minimização de sua função energia (Equação 2.4). Propõe-se que, de forma complementar à ação das forças internas e externas, uma força de nova natureza atue sobre os pontos do contorno de forma a alocá-los otimamente sob a perspectiva da melhor representação do contorno.

A Figura 3.4 ilustra, para o mesmo contorno buscado na Figura 3.2, por uso do mesmo número de iterações, o resultado da intervenção proposta. 


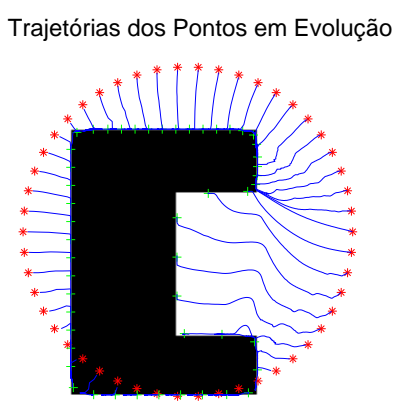

Contorno Identificado

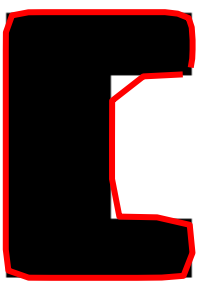

Figura 3.4: Trajetória descritas pelos pontos do contorno deformável em sua evolução sob ação complementar da força proposta: $(*)$ pontos conforme iniciados, (-) suas trajetórias e $(+)$ suas posições ao término das iterações

A Figura 3.5 apresenta os resultados obtidos por uso da solução proposta e da snake GVF, respectivamente.
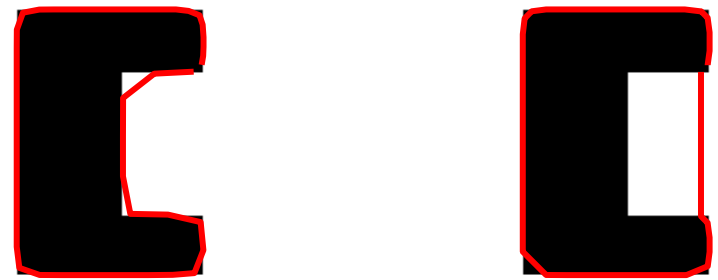

Figura 3.5: Contornos identificados por uso da solução proposta e da snake GVF 
Este capítulo é dedicado à formalização da proposta. O próximo tópico tratatá mais detalhadamente da metodologia e os tópicos subseqüentes serão dedicados à definição detalhada de suas etapas constituintes.

\subsection{Corrugação}

Esquematicamente, a metodologia proposta pode ser descrita conforme consta na Figura 3.6.

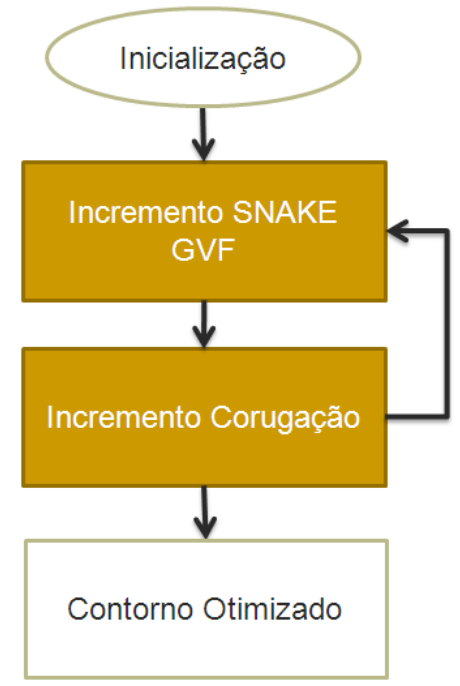

Figura 3.6: Metodologia proposta

Propõe-se que, intercalada às etapas de evolução do contorno em obediência às forças internas e externas, seja realizada uma intervenção com vistas à relocação dos pontos sobre o próprio contorno em busca da melhor representação do mesmo. Conforme proposto, além da busca pela minimização da função energia definida em KASS et al. (1988), a snake passa a incorporar sensibilidade às demandas específicas das regiões do contorno em seu processo de conformação.

Diferentemente das tradicionais forças internas e externas, portanto, a força proposta é orientada à alocação ótima dos pontos ao longo do contorno deformável. Fenomenologicamente, a ação da força proposta implica na apro- 
ximação ou no afastamento dos pontos ao longo do contorno, daí a denominação corrugação.

Mais especificamente, a força de corrugação proposta atua de modo a minimizar a carência por pontos do contorno através da definição ótima de suas posições segundo o critério de fidelidade entre contorno deformável e o contorno buscado. Fenomenologicamente a intervenção ocorre de modo a:

- afastar os pontos em regiões nas quais esta intervenção implica, sob o ponto de vista global do contorno, maior disponibilidade de pontos para as regiões mais deficitárias;

- aproximar os pontos em regiões nas quais esta intervenção se justifica à luz do aumento da fidelidade da representação de detalhes, mesmo quando observada a eventual diminuição da fidelidade da representação de outras regiões.

A Figura 3.7 ilustra qualitativamente o resultado da intervenção proposta. Conforme consta na imagem, o reposicionamento dos pontos é fator provedor de maior enquadramento do aspecto recomposto ao contorno buscado.
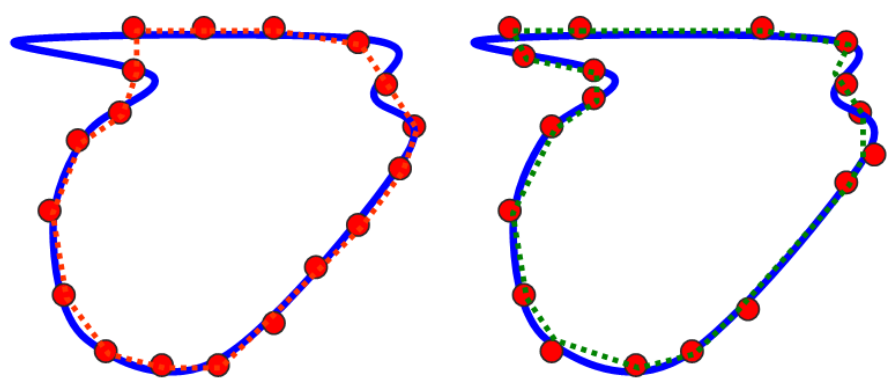

Figura 3.7: Resultado qualitativo da força de corrugação 
Subjacentes à relocação dos pontos constam duas etapas discretas bastante características, a caracterização local e a corrugação propriamente dita. Na etapa denominada caracterização local as variadas regiões do contorno são qualificadas segundo sua contribuição para a definição da fidelidade do contorno; na etapa denominada corrugação as definições locais e absolutas são contextualizados no cenário geral e utilizadas como argumento na definição das estratégias ótimas de relocação dos pontos. O próximo tópico tratará da etapa de caracterização local, o tópico seguinte abordará a etapa de corrugação.

\subsection{Caracterização Local}

Define-se por caracterização local a avaliação dos pontos segundo suas contribuições para a definição do contorno. Em outras palavras, esta etapa consiste na análise dos posicionamentos dos pontos quanto às suas participações na definição do dado aspecto. Resultam da caracterização local índices que quantificam a contribuição do ponto denominados mérito.

Definida de outra forma, a caracterização local consiste do mapeamento do contorno em um espaço de parâmetros $H(s)=(z(s), h(s))$. O parâmetro $z(s)$ é definido como avanço do ponto e o parâmetro $h(s)$ é definido como o mérito do ponto. A Figura 3.8 ilustra o procedimento.
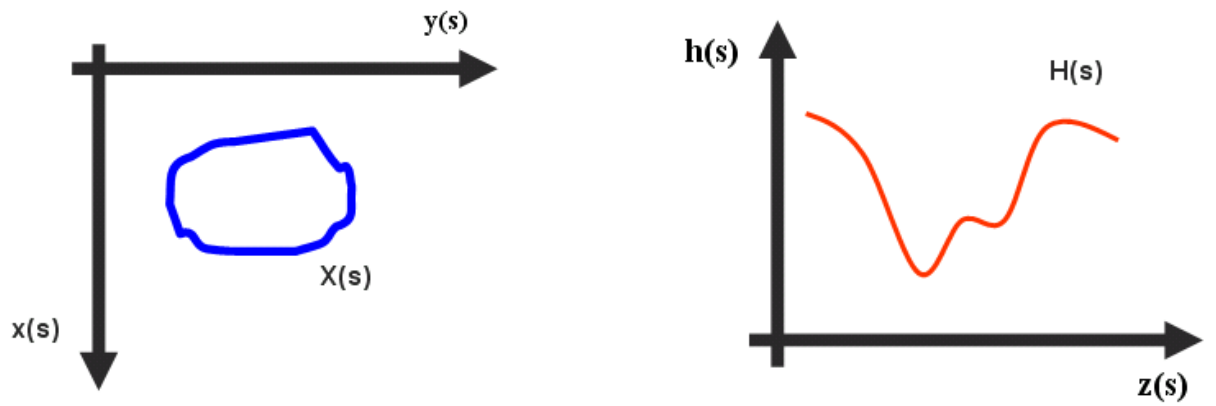

Figura 3.8: Domínio espacial do sinal e espaço de parâmetros 
Os subtópicos seguintes abordarão mais detalhadamente as etapas.

\subsubsection{Avanço $\mathrm{z}(\mathrm{s})$}

Por fins práticos, a utilização do parâmetro avanço em substituição ao parâmetro comprimento de arco se dá para permitir algum nível de atenção diferenciada às regiões. De forma análoga ao tratamento dado aos parâmetos $\alpha(s)$ e $\beta(s)$, a sintonia da fução $z(s)$ deve ser feita com base no conhecimento a priori do contono buscado. Será assumido, sem perda de generalidade, que

$$
z(s)=s
$$

\subsubsection{Mérito $\mathrm{h}(\mathrm{s})$}

Define-se neste trabalho por mérito de um ponto um índice que quantifica a sua contribuição para a definição de um dado aspecto do contorno. A pontos que representam detalhes do contorno correspondem maiores méritos e, analogamente, pontos menos expressivos na definição do contorno correspondem a menores méritos.

As funções por meio das quais os pontos da snake são avaliados quanto à contribuição de sua vizinhança para a fidelidade da representação do contorno, por sua vez, são denominadas funções de mérito. Foram propostas e estudadas várias funções de mérito. Os subtópicos subsequentes serão dedicados à apresentação das funções de mérito pseudo-curvatura, rugosidade e equalizadora.

\section{Pseudo-curvatura}

A função de mérito pseudo-curvatura, conforme o termo antecipa, consiste em atribuir ao mérito do ponto uma métrica da curvatura do contorno na sua vizinhança. A Figura 3.9 apresenta o mérito obtido por uso da função pseudocurvatura em função do argumento variação angular. O argumento variação 
angular é definido como a diferença entre as inclinações do segumento posterior ao nó $\left(\theta_{f}\right)$ avaliado e anterior ao nó $\left(\theta_{i}\right)$ avaliado.

\section{Função de Mérito Pseudo Curvatura}

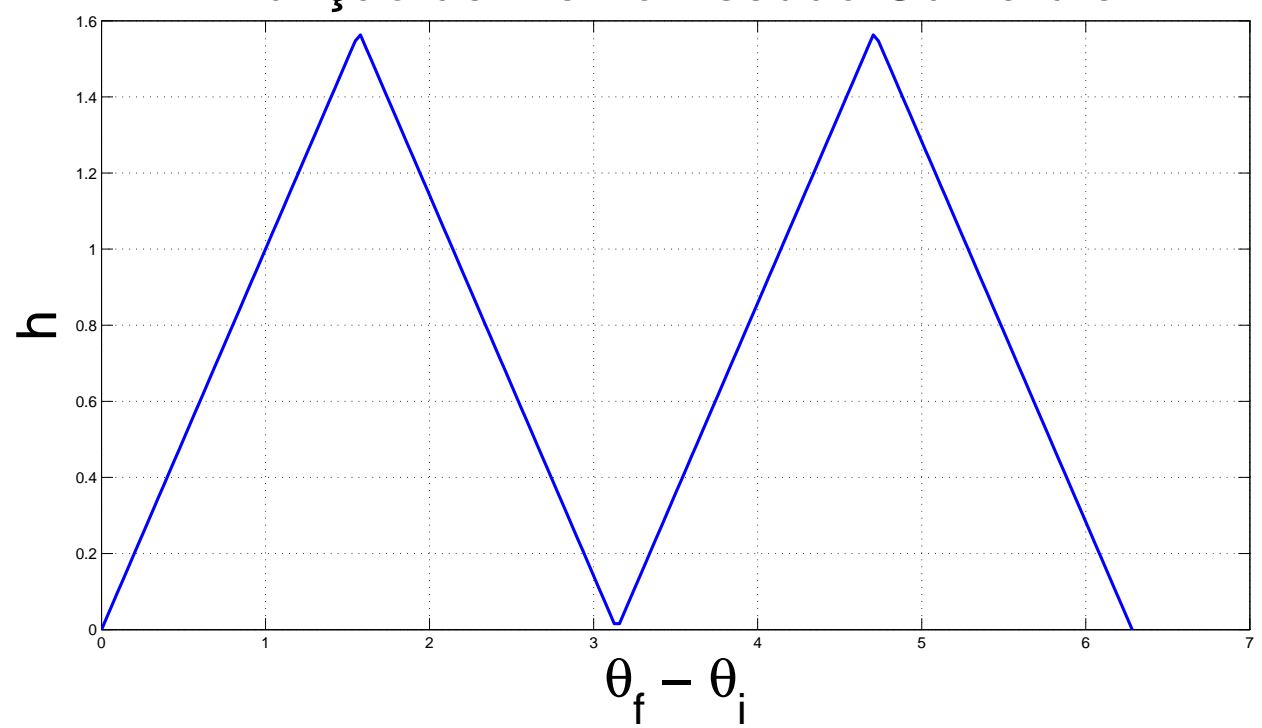

Figura 3.9: Função de mérito pseudo-curvatura como função da inclinação dos segmentos sucessor $\theta_{f}$ e antecessor $\theta_{i}$ do ponto

As Figuras 3.10, 3.11, 3.12, 3.13 e 3.14 ilustram a aplicação da função de mérito pseudo-curvatura a curvas características. 

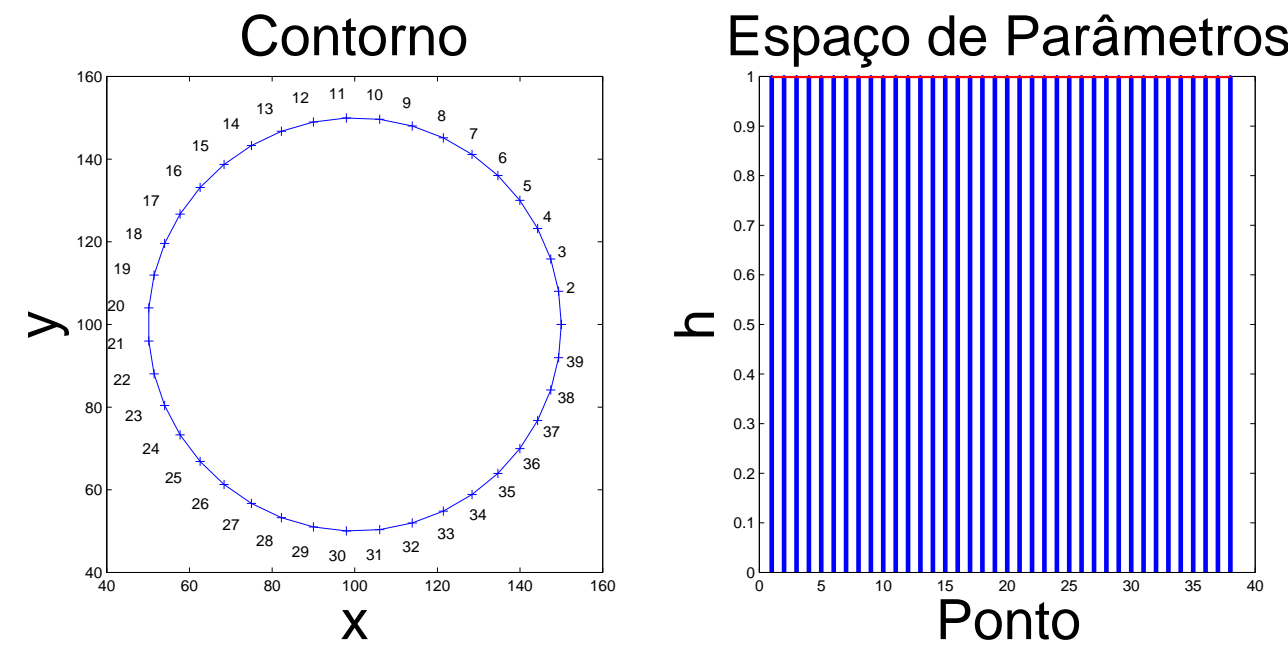

Figura 3.10: Contorno circular e espaço de parâmetro para a função de mérito pseudo-curvatura
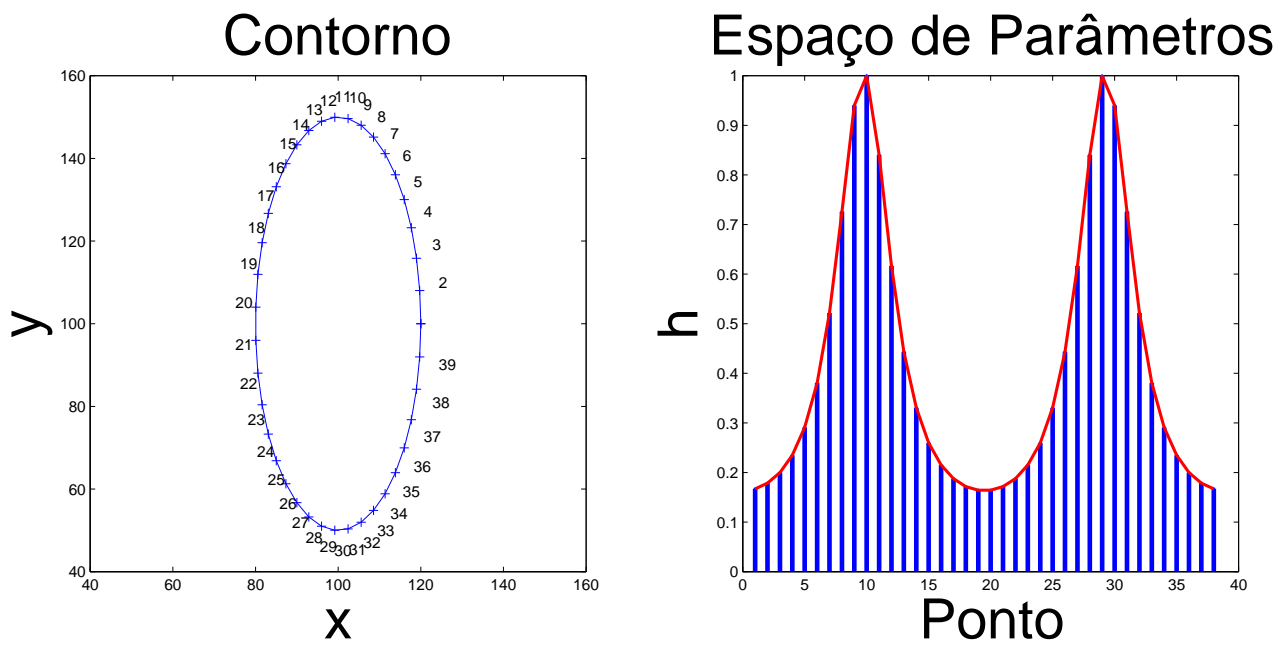

Figura 3.11: Contorno elipsoidal e espaço de parâmetro para a função de mérito pseudo-curvatura 

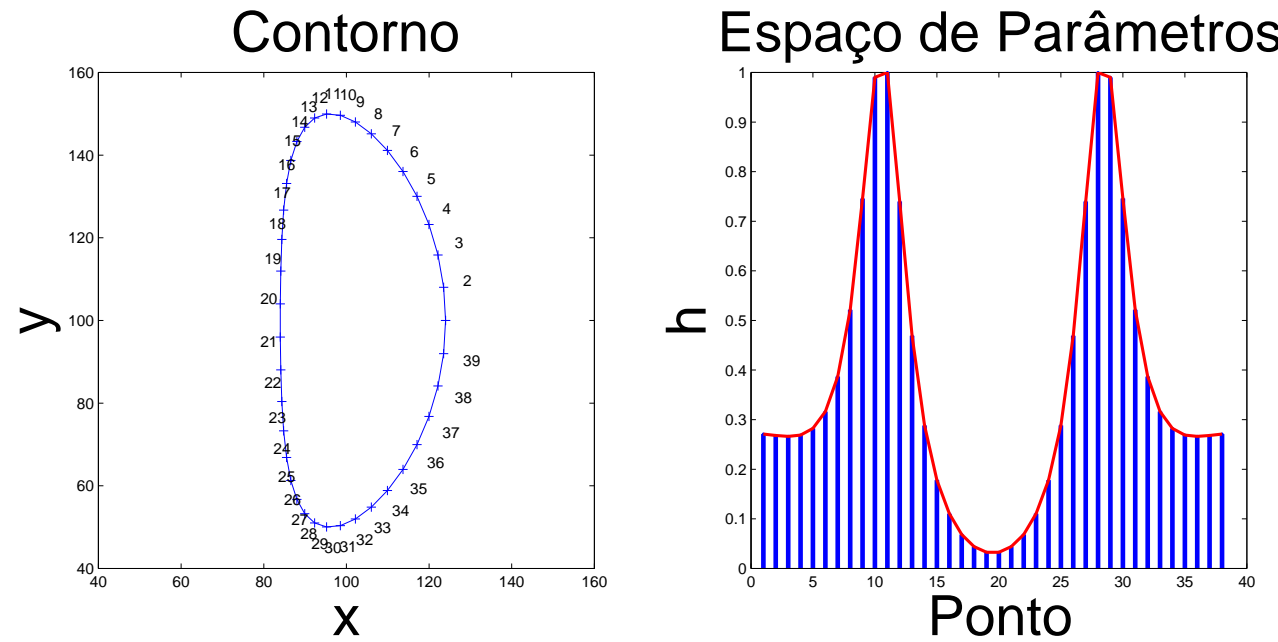

Figura 3.12: Contorno em forma de feijão e espaço de parâmetro para a função de mérito pseudo-curvatura
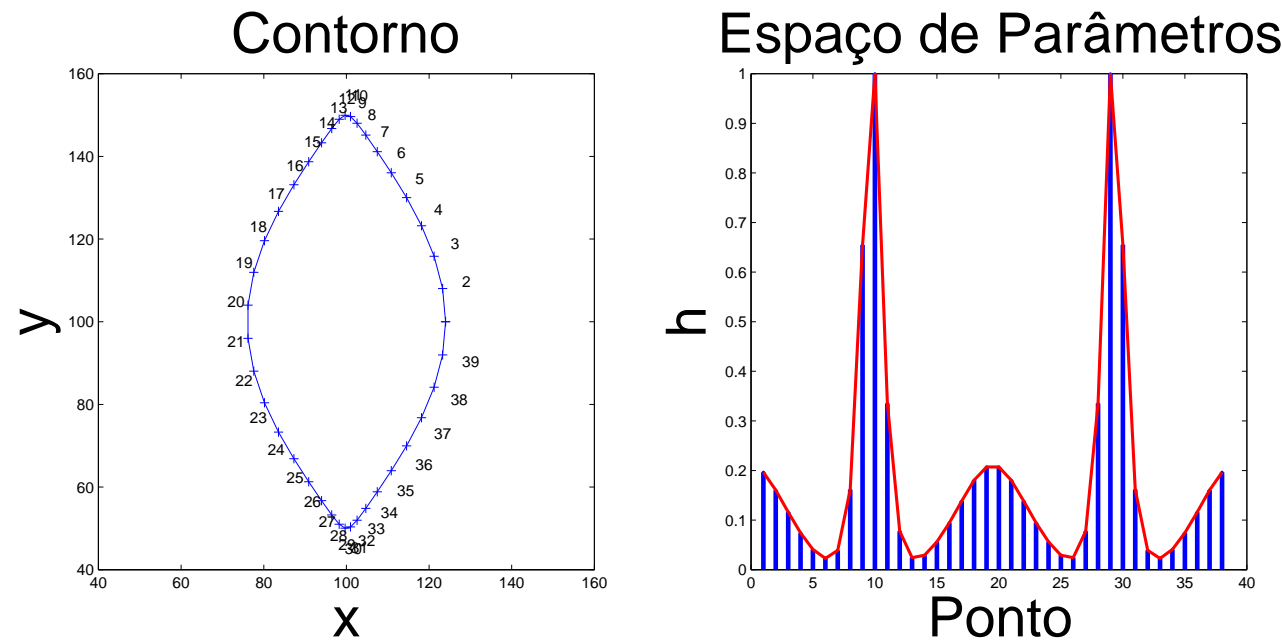

Figura 3.13: Contorno fusiforme e espaço de parâmetro para a função de mérito pseudo-curvatura 

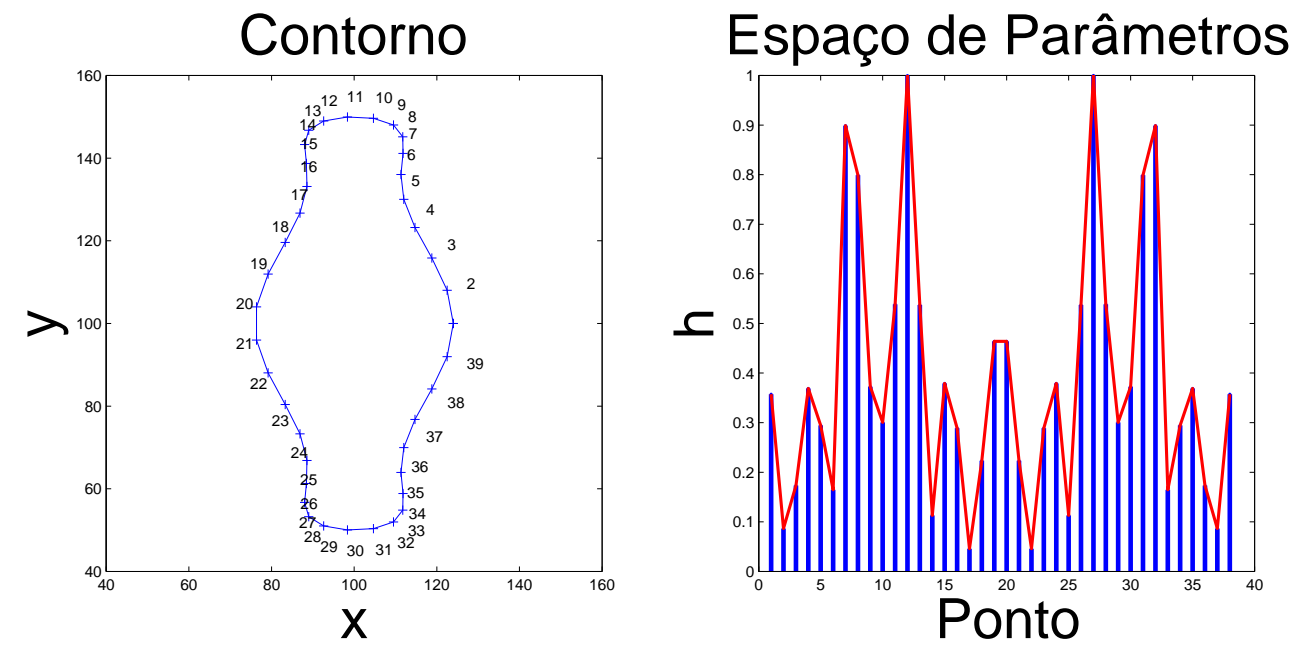

Figura 3.14: Contorno em forma de fechadura e espaço de parâmetro para a função de mérito pseudo-curvatura

\section{Rugosidade}

A função de mérito rugosidade define como mérito do ponto a métrica de rugosidade definida na equação 3.2

$$
h=\frac{\left\|r_{i}-r_{i-1}\right\|+\left\|r_{i+1}-r_{i}\right\|-\left\|r_{i+1}-r_{i-1}\right\|}{\left\|r_{i+1}-r_{i-1}\right\|^{2}}
$$

na qual $r_{i}$ representa as coordenadas do nó i do contorno e, $r_{i-1}$ e $r_{i+1}$, os seus antecessores e sucessores respectivamente.

As Figuras 3.15, 3.16, 3.17, 3.18 e 3.19 ilustram os resultados obtidos pela utilização da função de mérito rugosidade 

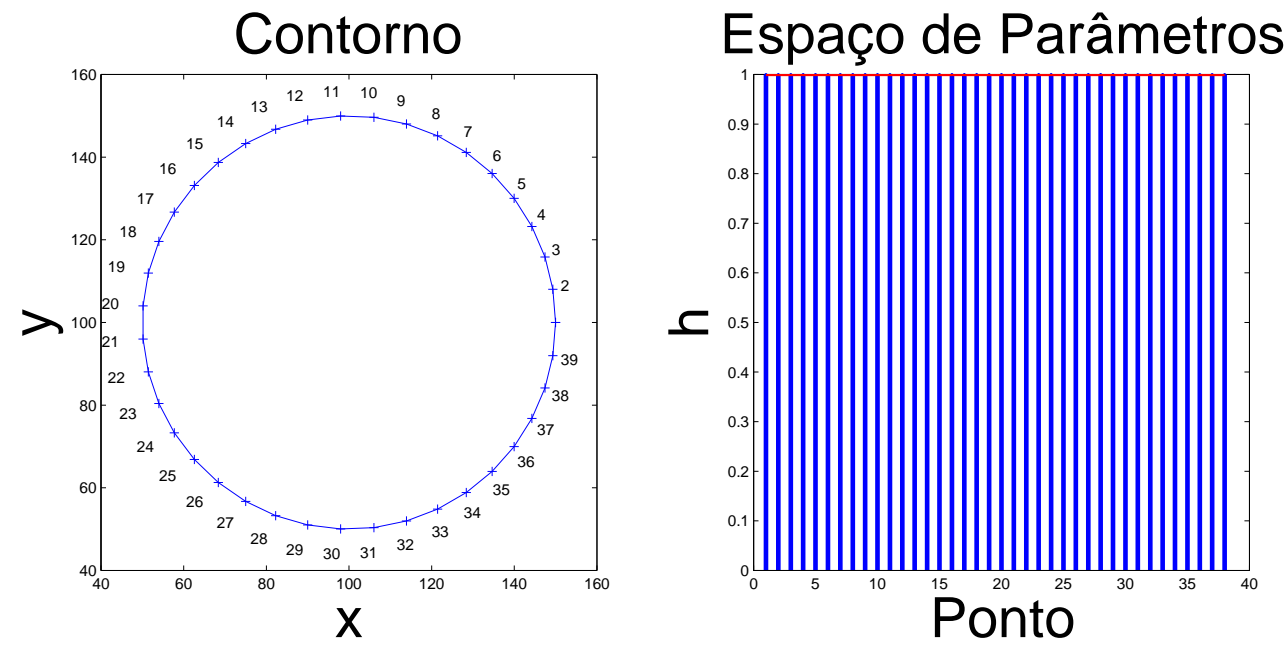

Figura 3.15: Contorno circular e espaço de parâmetro para a função de mérito rugosidade
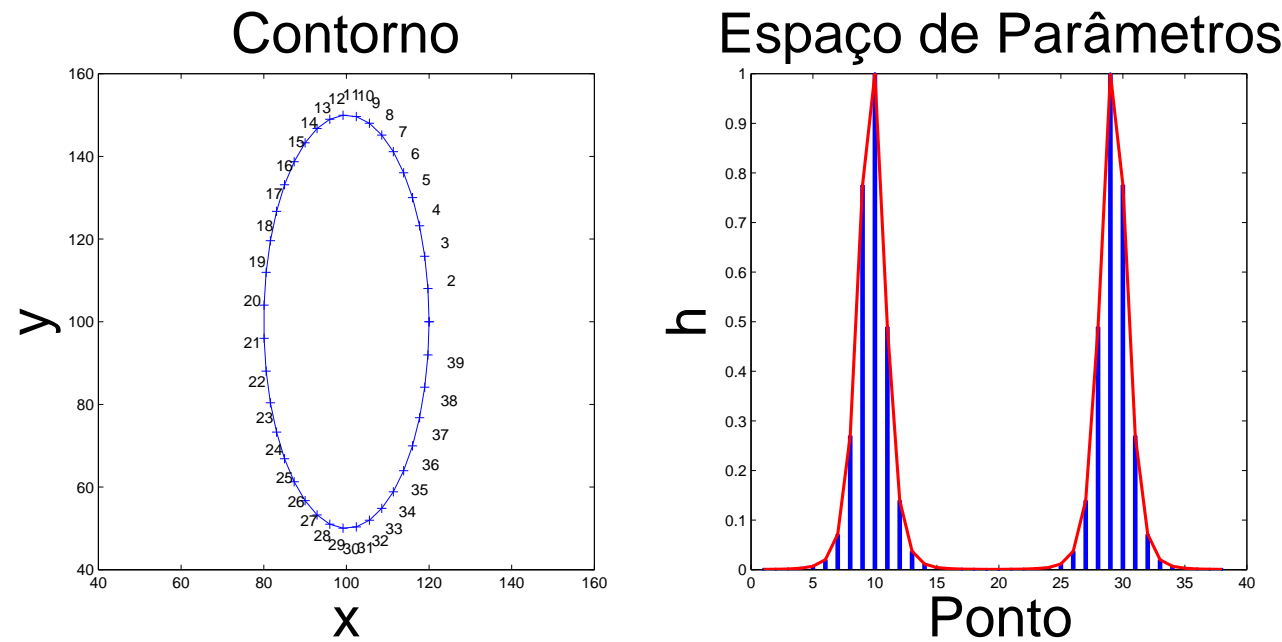

Figura 3.16: Contorno elipsoidal e espaço de parâmetro para a função de mérito rugosidade 

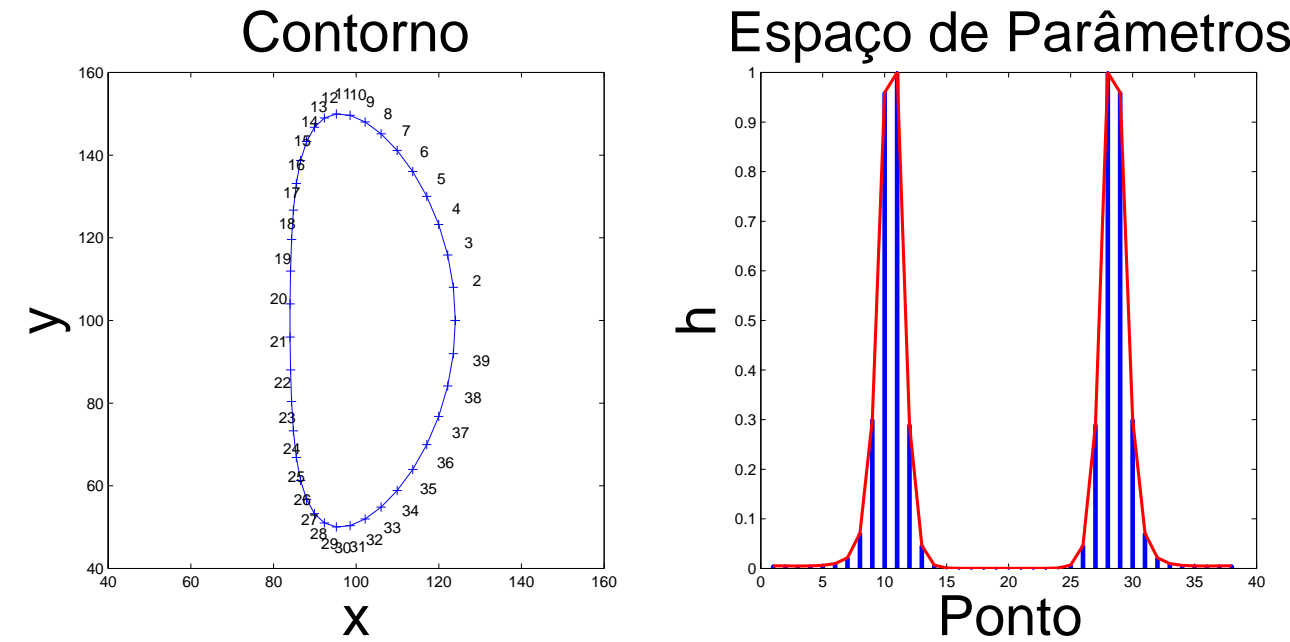

Figura 3.17: Contorno em forma de feijão e espaço de parâmetro para a função de mérito rugosidade
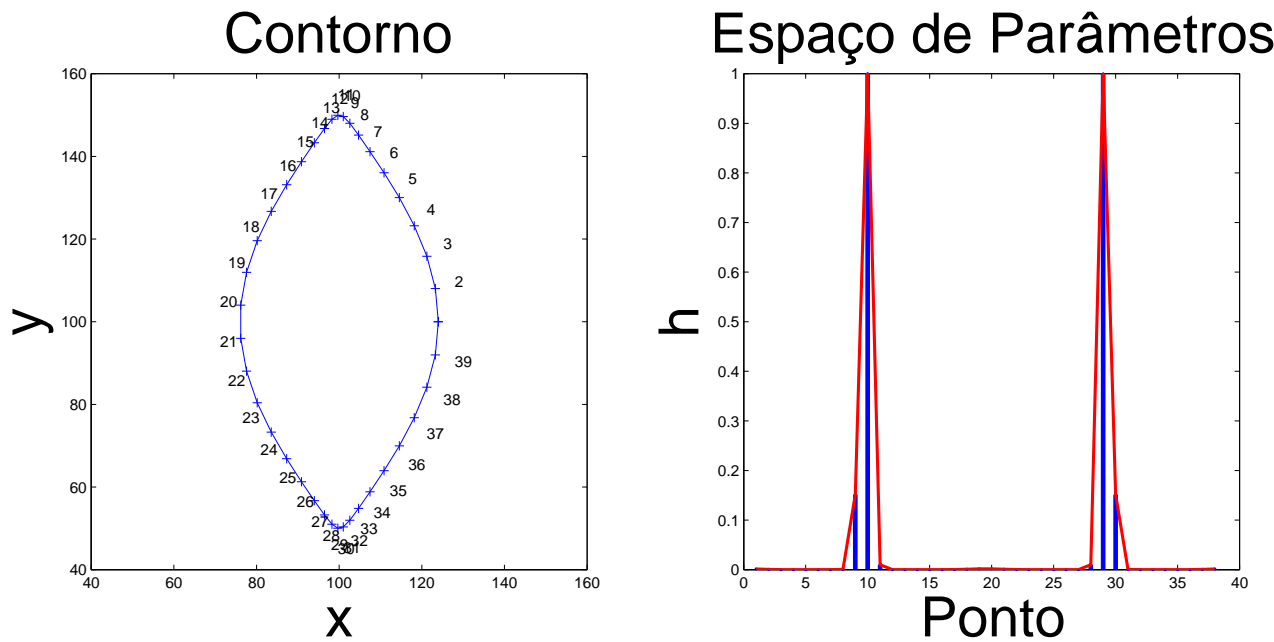

Figura 3.18: Contorno fusiforme e espaço de parâmetro para a função de mérito rugosidade 

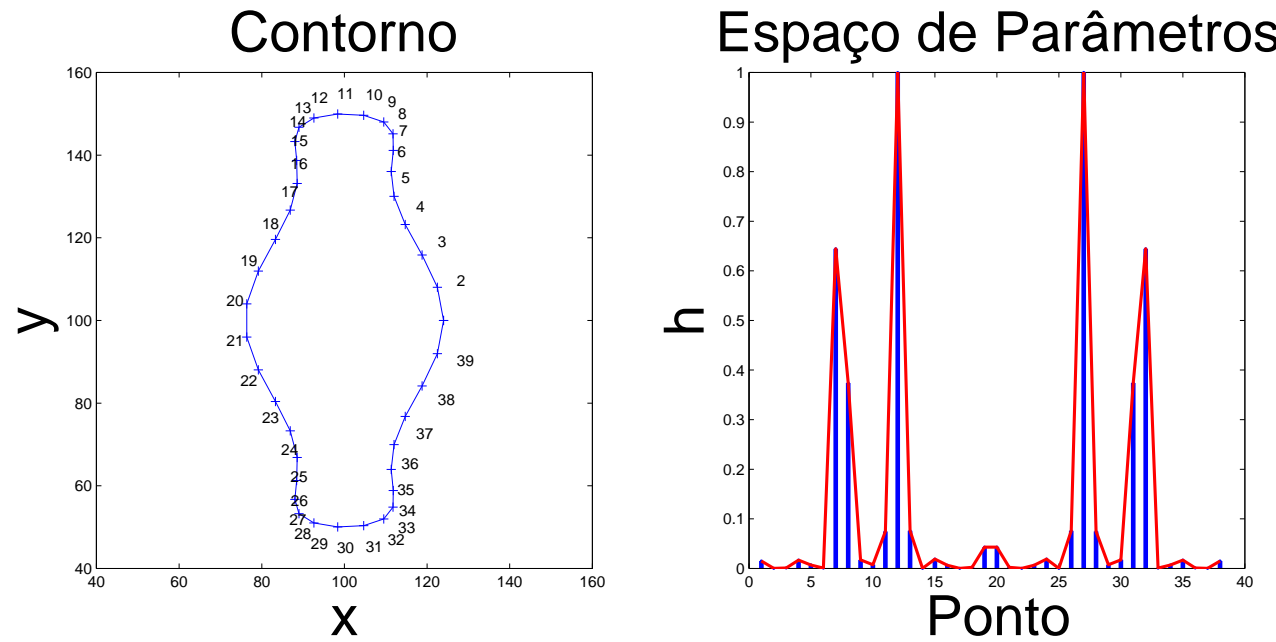

Figura 3.19: Contorno em forma de fechadura e espaço de parâmetro para a função de mérito rugosidade

\section{Equalizadora}

A função de mérito equalizadora consiste na definição de um valor constante de mérito a todos os pontos. A função de mérito equalizadora implica na tendência dos pontos do contorno a esparsarem-se uniformemente ao longo do contorno. Matematicamente a função equalizadora é definida como na equação 3.3

$$
h(s)=k
$$

\subsection{Corrugação Propriamente Dita}

A etapa referida por corrugação consiste na definição das novas posições dos pontos do contorno deformável na minimização de seu déficite. À luz dos conceitos definidos nesse trabalho, a etapa de optimização consiste na minimização de uma função denominada função morfológica de energia definida na equação 3.4. 


$$
\epsilon_{M O R F}=\int_{0}^{1} u(s) h(s)+v(s)\left|\frac{\partial H(s)}{\partial s}\right|^{2} d s
$$

Os parâmetros $u(s)$ e $v(s)$ correspondem aos pesos normalizados atribuídos às componentes mérito $(u(s) h(s))$ e distensão $\left((s)\left|\frac{\partial H(s)}{\partial s}\right|^{2}\right)$, respectivamente. A componente de mérito corresponde à contribuição do aspecto do contorno avaliada segundo a função de mérito. A componente de distenção, por sua vez, corresponde à contribuição do afastamento dos pontos do contorno.

A proposta de definir um processo de minimização da função morfológica de energia tolerante à eventual incorporação de novas restrições e excitações definiu demandas específicas para o procedimento. Estas propriedades podem ser elencadas como:

- Modelo dinâmico - o modelo deve satisfazer a restrições variantes no tempo e estáticas;

- Dinâmica interativa - a dinâmica das partes é influenciada pelos estados das demais partes constituintes;

- Generalidade - eventuais novas excitações não devem demandar modificações topológicas significantes no modelo. O sistema deve tolerar formulações que influenciem parâmetros arbitrários do modelo;

- Modularidade - novas excitações não devem repercutir sobre as excitações existentes;

- Robustez - devem ser toleradas excitações e restrições singulares.

Conforme proposto, a minimização da função morfológica de energia ocorre pelo deslocamento dos pontos ao longo do contorno original sob ação da força de corrugação. O respeito a essa trajetória arbitrária, por sua vez, não é consistente com as forças correspondentes ao oposto do gradiente da energia potencial. Disto decorre que, por analogia aos sistemas mecânicos, a promoção da variação da quantidade do movimento dos pontos deve-se, além de às componentes conhecidas 
de força, a forças de outra natureza. Estas forças serão referidas por forças de restrição.

Em verdade, as forças de restrição não são necessariamente associadas a um ator físico. Não têm origens reais e sua ação é conhecida apenas segundo seu efeito no sistema. Podem, entretanto, em reforço à plausibilidade da associação com problemas mecânico, ser associadas à reação normal da superfície de um guia perfeito. A sua implementação computacional, portanto, consiste da simulação da evolução de um sistema mecânico para a configuração menos energética. 


\section{Capítulo 4}

\section{Resultados e Discussões}

Este capítulo é dedicado à apresentação dos resultados da pesquisa. Dada a grande difusão e reconhecimento da técnica GVF como de excelente qualidade, julgou-se pela conveniência de utilizá-la na comparação com os resultados obtidos através da metodologia proposta. Constam nesse capítulo, portanto, os contornos identificados por uso dos contornos deformáveis GVF e por uso da metodologia proposta - força de corrugação. O capítulo seguinte será dedicado às conclusões.

\subsection{Banco de Imagens}

Pela observação do aspecto controlabilidade, optou-se por compor um banco formado por imagens teste formado por imagens sintéticas controladas. Pôde-se, dessa forma, promover cenários com características controladas que confrontaram as duas técnicas (GVF e corrugação) com as limitações dos contornos deformáveis. As Figuras 4.1, 4.2, 4.3 e 4.4 apresentam as imagens sintética simples 1 (SS1), sintética complexa 1 (SC1), sintética complexa 2 (SC2) e sintética complexa 3 (SC3) respectivamente. 


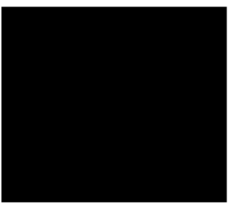

Figura 4.1: Imagem sintética simples SS1

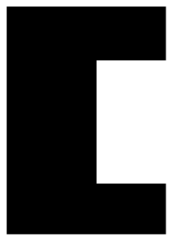

Figura 4.2: Imagem sintética complexa SC1

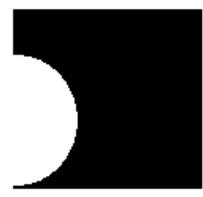

Figura 4.3: Imagem sintética complexa SC2 


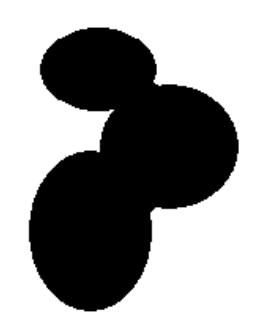

Figura 4.4: Imagem sintética complexa SC3

Os tópicos subsequentes apresentarão os resultados obtidos para cada uma das imagens do banco de teste. As simulações foram conduzidas sobre duas plataformas. A geração do campo de forças externas GVF foi feita por uso de um aplicativo Windows desenvolvido em $\mathrm{C}++$. A animação dos contornos foi desenvolvida em Matlab’.

\subsection{Imagem Sintética Simples 1 - SS1}

Para a imagem SS1 foram utilizadas 80000 iterações tanto para a snake GVF quanto para a snake corrugada. A Figura 4.5 apresenta o resultado obtido pelo uso função de mérito equalizadora.

A Figura 4.6 apresenta o resultado obtido pelo uso função de mérito pseudocurvatura. 
Iteração 80000

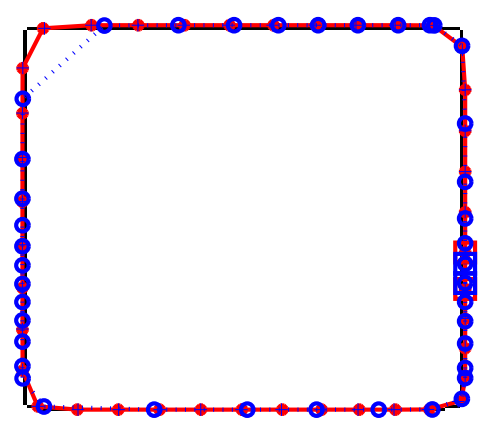

Figura 4.5: Contorno da figura SS1 identificado por modelo deformável: GVF (azul) e corrugado com função de mérito equalizadora (vermelho)

Iteração 80000

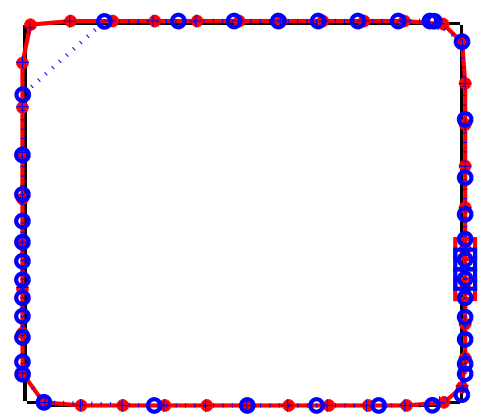

Figura 4.6: Contorno da figura SS1 identificado por modelo deformável: GVF (azul) e corrugado com função de mérito pseudo-curvatura (vermelho) 
A Figura 4.7 apresenta o resultado obtido pelo uso função de mérito rugosidade.

Iteração 80000

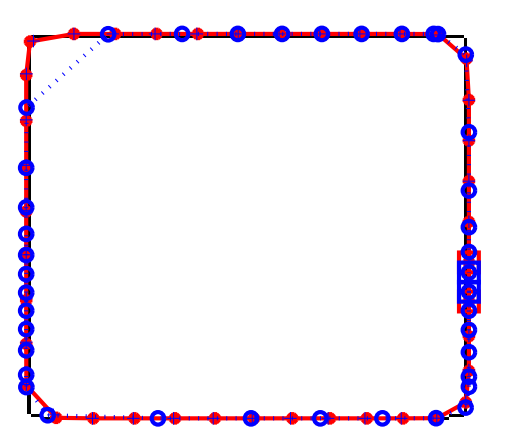

Figura 4.7: Contorno da figura SS1 identificado por modelo deformável: GVF (azul) e corrugado com função de mérito rugosidade (vermelho)

\subsection{Imagem Sintética Complexa 1 - SC1}

Para a imagem SC1 foram utilizadas 150000 iterações tanto para a snake GVF quanto para a snake corrugada. A Figura 4.8 apresenta o resultado obtido pelo uso função de mérito equalizadora.

A Figura 4.9 apresenta o resultado obtido pelo uso função de mérito pseudocurvatura. 
Iteração 150000

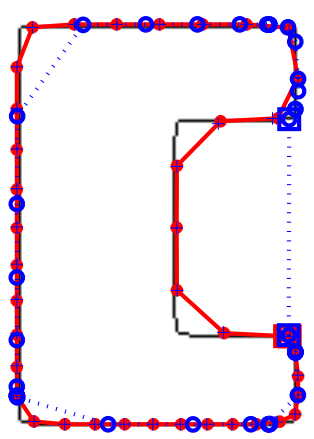

Figura 4.8: Contorno da figura SC1 identificado por modelo deformável: GVF (azul) e corrugado com função de mérito equalizadora (vermelho)

Iteração 150000

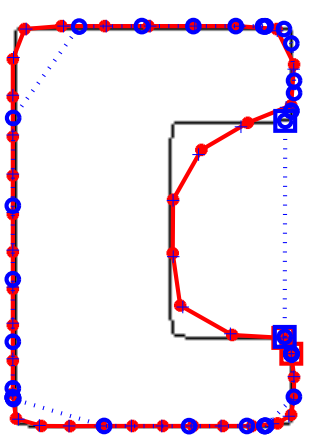

Figura 4.9: Contorno da figura SC1 identificado por modelo deformável: GVF (azul) e corrugado com função de mérito pseudo-curvatura (vermelho)

A Figura 4.10 apresenta o resultado obtido pelo uso função de mérito rugosidade. 
Iteração 150000

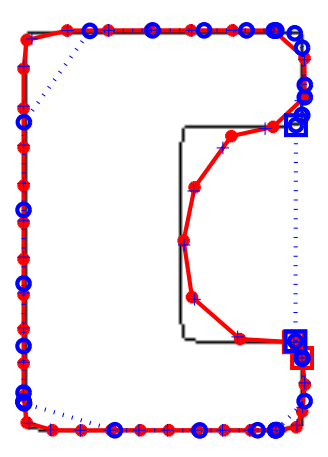

Figura 4.10: Contorno da figura SC1 identificado por modelo deformável: GVF (azul) e corrugado com função de mérito rugosidade (vermelho)

\subsection{Imagem Sintética Complexa 2 - SC2}

Para a imagem SC2 foram utilizadas 60000 iterações tanto para a snake GVF quanto para a snake corrugada. A Figura 4.11 apresenta o resultado obtido pelo uso função de mérito equalizadora.

A Figura 4.12 apresenta o resultado obtido pelo uso função de mérito pseudocurvatura. 
Iteração 60000

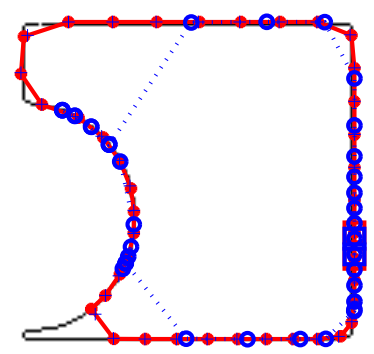

Figura 4.11: Contorno da figura SC2 identificado por modelo deformável: GVF (azul) e corrugado com função de mérito equalizadora (vermelho)

Iteração 60000

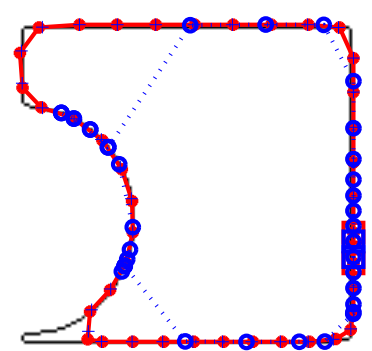

Figura 4.12: Contorno da figura SC2 identificado por modelo deformável: GVF (azul) e corrugado com função de mérito pseudo-curvatura (vermelho)

A Figura 4.13 apresenta o resultado obtido pelo uso função de mérito rugosidade. 
Iteração 60000

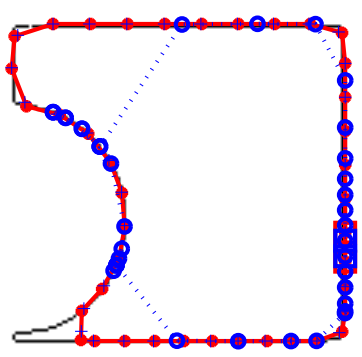

Figura 4.13: Contorno da figura SC2 identificado por modelo deformável: GVF (azul) e corrugado com função de mérito rugosidade (vermelho)

\subsection{Imagem Sintética Complexa 3 - SC3}

Para a imagem SC3 foram utilizadas 60000 iterações tanto para a snake GVF quanto para a snake corrugada. A Figura 4.14 apresenta o resultado obtido pelo uso função de mérito equalizadora.

A Figura 4.15 apresenta o resultado obtido pelo uso função de mérito pseudocurvatura. 


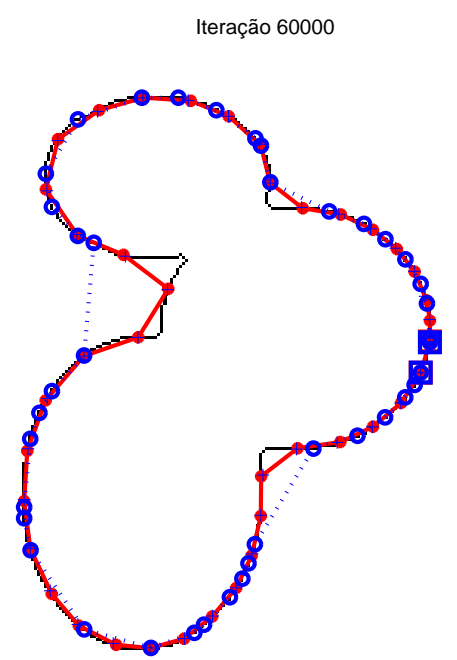

Figura 4.14: Contorno da figura SC3 identificado por modelo deformável: GVF (azul) e corrugado com função de mérito equalizadora (vermelho)

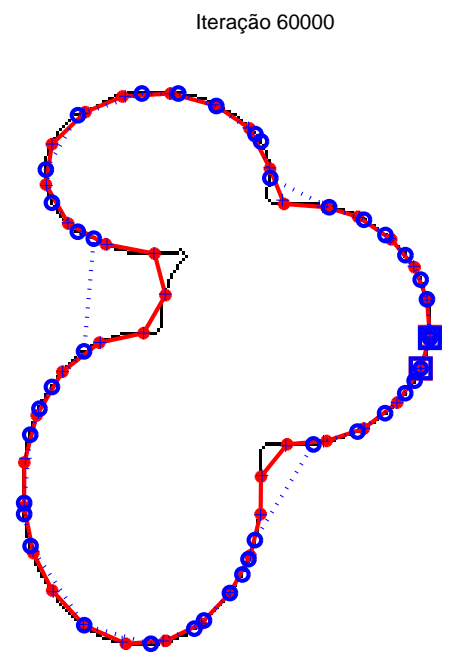

Figura 4.15: Contorno da figura SC3 identificado por modelo deformável: GVF (azul) e corrugado com função de mérito pseudo-curvatura (vermelho) 
A Figura 4.16 apresenta o resultado obtido pelo uso função de mérito rugosidade.

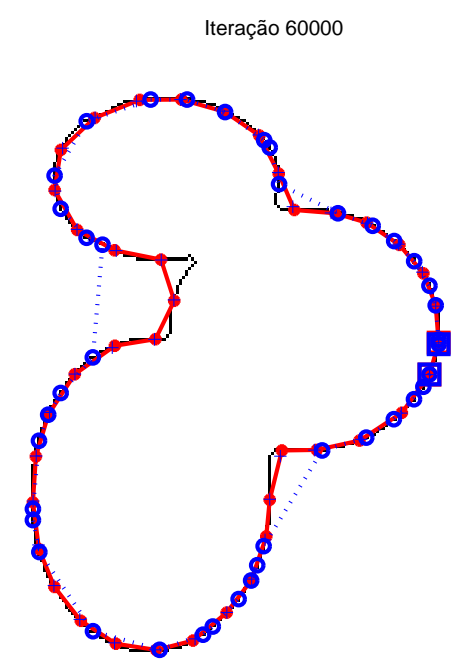

Figura 4.16: Contorno da figura SC1 identificado por modelo deformável: GVF (azul) e corrugado com função de mérito rugosidade (vermelho)

\subsection{Análise dos Resultados}

Os resultados evidenciam que, conforme proposto, a força de corrugação impõe à dinâmica evolutiva dos contornos deformáveis atitudes complementares às associadas à minimização de sua função energia (equação 2.4) definida em sua formulação original. Seja, ilustrativamente, o resultado apresentado na Figura 4.17. Conforme evidenciado, as trajetórias descritas pelos pontos da snake corrugada, apesar de compatíveis com a busca do contorno de interesse, não devem-se exclusivamente à ação das forças internas e externas (GVF). 
GVF, Snake GVF e Snake Corrugada

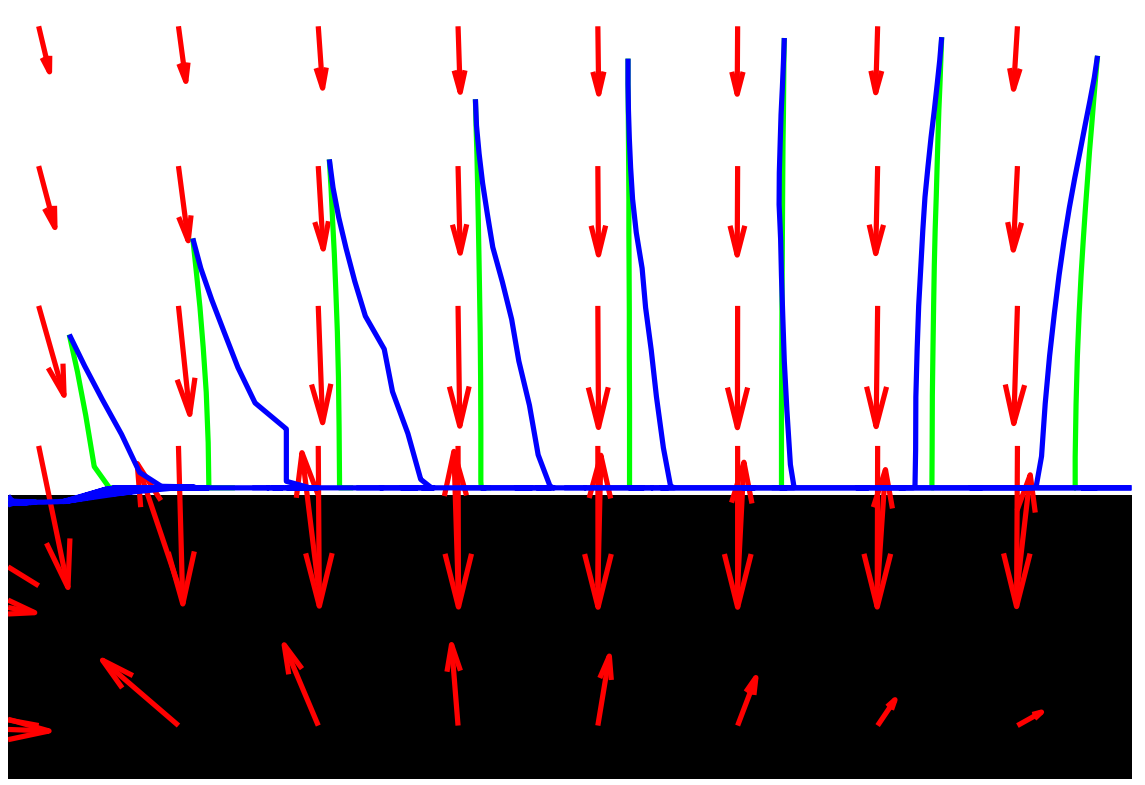

Figura 4.17: Trajetória descrita por contornos deformáveis: $(\longleftarrow)$ campo de força externa, (- verde) Snake GVF e (- azul) Snake Corrugada

No que define o ineditismo da proposição, a ação da força corrugadora anima os pontos do contorno de modo a alocá-los convenientemente com vistas à melhor representação do contorno. Conforme evidenciado no detalhe à Figura 4.18, o resultado da ação da força de corrugação é a disponibilização de pontos do contorno para investigar regiões da imagem desprevilegiadas pela formulação tradicional. Nota-se que, apesar de consistentes com o campo de força externa, as trajetórias descritas pela snake GVF são tais que conduzem os pontos ao agrupamento e ao consequente enriquecimento na representação de regiões, o que ocorre ao elevado custo da negligência na representação de outros aspectos do contorno de interesse. 


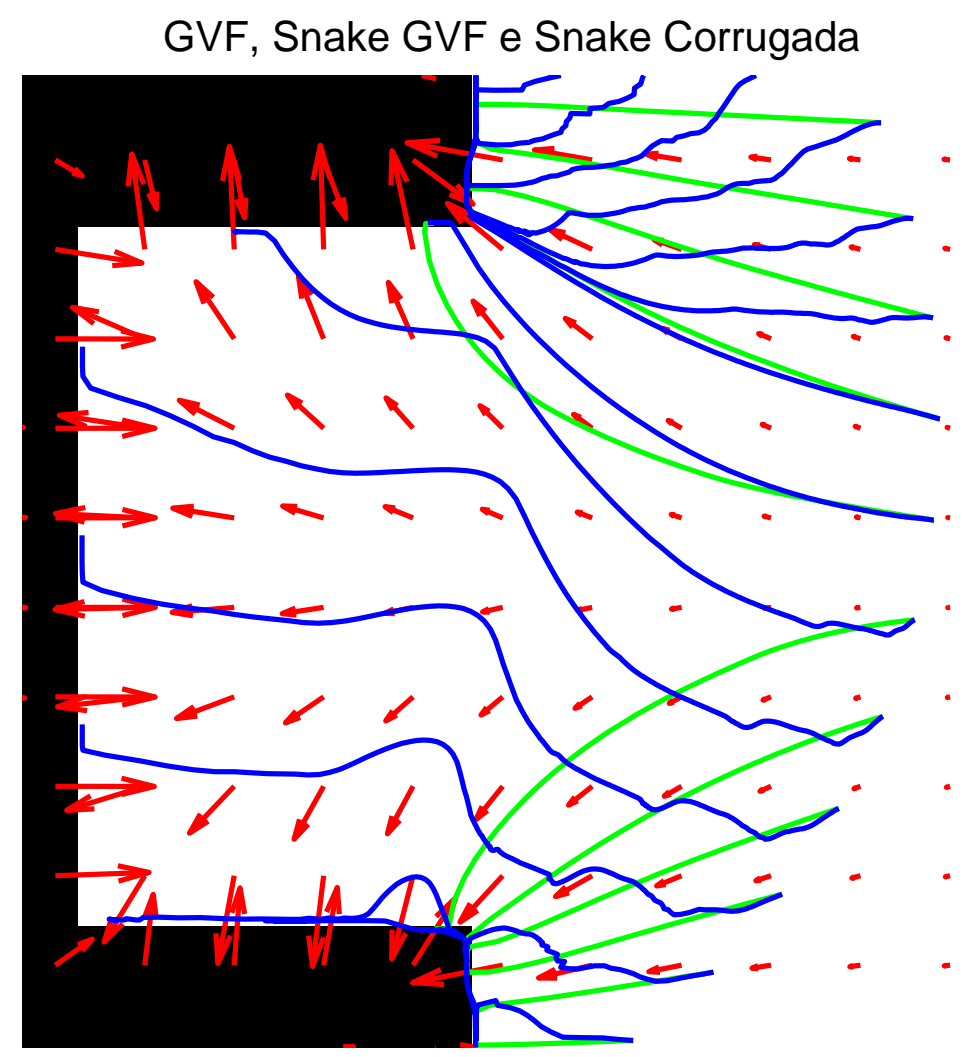

Figura 4.18: Disponibilização de pontos para investigar regiões do elemento de interessa na imagem não contempladas pela snake GVF: $(\leftarrow)$ campo de força externa, (- verde) trajetórias dos pontos da Snake GVF e (- azul) trajetória dos pontos da Snake corrugada

Com efeito, conforme consta nas Figuras 4.5, 4.6, 4.7, 4.8, 4.9, 4.10, 4.11, $4.12,4.13,4.14,4.15$ e 4.16 , a força corrugadora incrementa substancialmente a capacidade do contorno deformável de aproximar o elemento de interesse na imagem. 


\subsection{Análise dos Resultados Quanto às Funções de Mérito}

A função de mérito equalizadora é robusta e apresenta como principal característica a orientação do contorno à definição de pontos igualmente esparsados. O seu resultado, portanto, é evitar adensamentos e esparsamentos inadequados pela uniformização da densidade de pontos em todo o contorno. Os resultados demonstraram que esta qualidade da intervenção é sempre útil mas não explora toda a filosofia proposta. Por uso da função equalisadora pontos podem estacionar em regiões do contorno cuja representação poderia ser atendida pelo uso de menor densidade (de pontos).

As funções de mérito rugosidade e pseudo-curvatura, diferentemente, previlegiam regiões nas quais os pontos são mais necessários. Além de evitar os adensamentos, as funções de mérito rugosidade e pseudo-curvatura são sensíveis à eventual possibilidade de, por exemplo, utilizar menos pontos para representar regiões do contorno com menor composição harmônica quando esta intervenção, sob o ponto de vista global, implicar em representação global mais fiel. Ao fazê-lo, portanto, as funções de mérito rugosidade e pseudo-curvatura enriquecem regiões do contorno onde a complexidade do aspecto demanda maior número de pontos. Qualitativamente, não foram observadas diferenças significativas entre os seus resultados (rugosidade e pseudo-curvatura). Observou-se que as diferenças entre ambas recaem mais notadamente sobre a assinatura da densidade de pontos ao longo do contorno. As Figuras 4.19 e 4.20 ilustram o fato para contornos sintéticos de parâmetros bem definidos. 

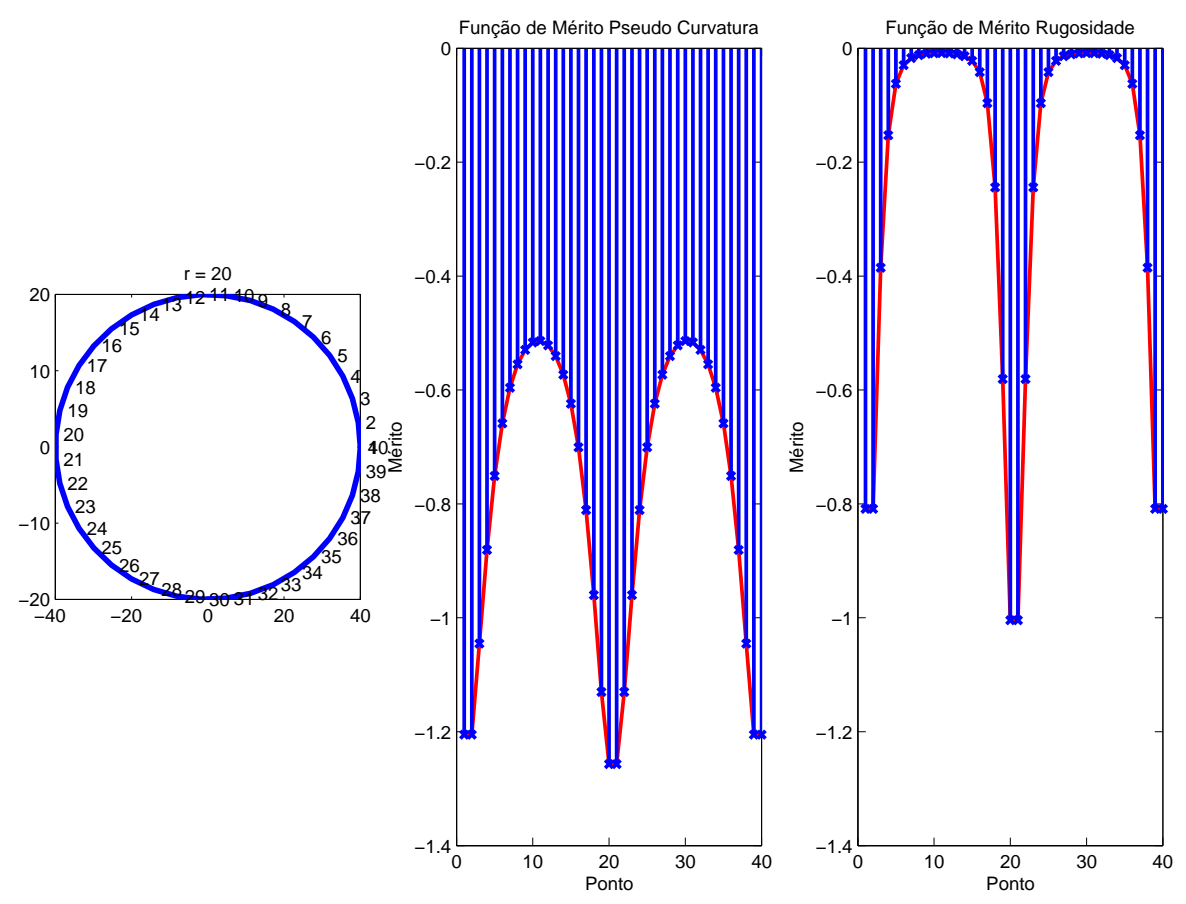

Figura 4.19: Méritos calculados por uso das funções pseudo-curvatura e rugosidade para um contorno elíptico 


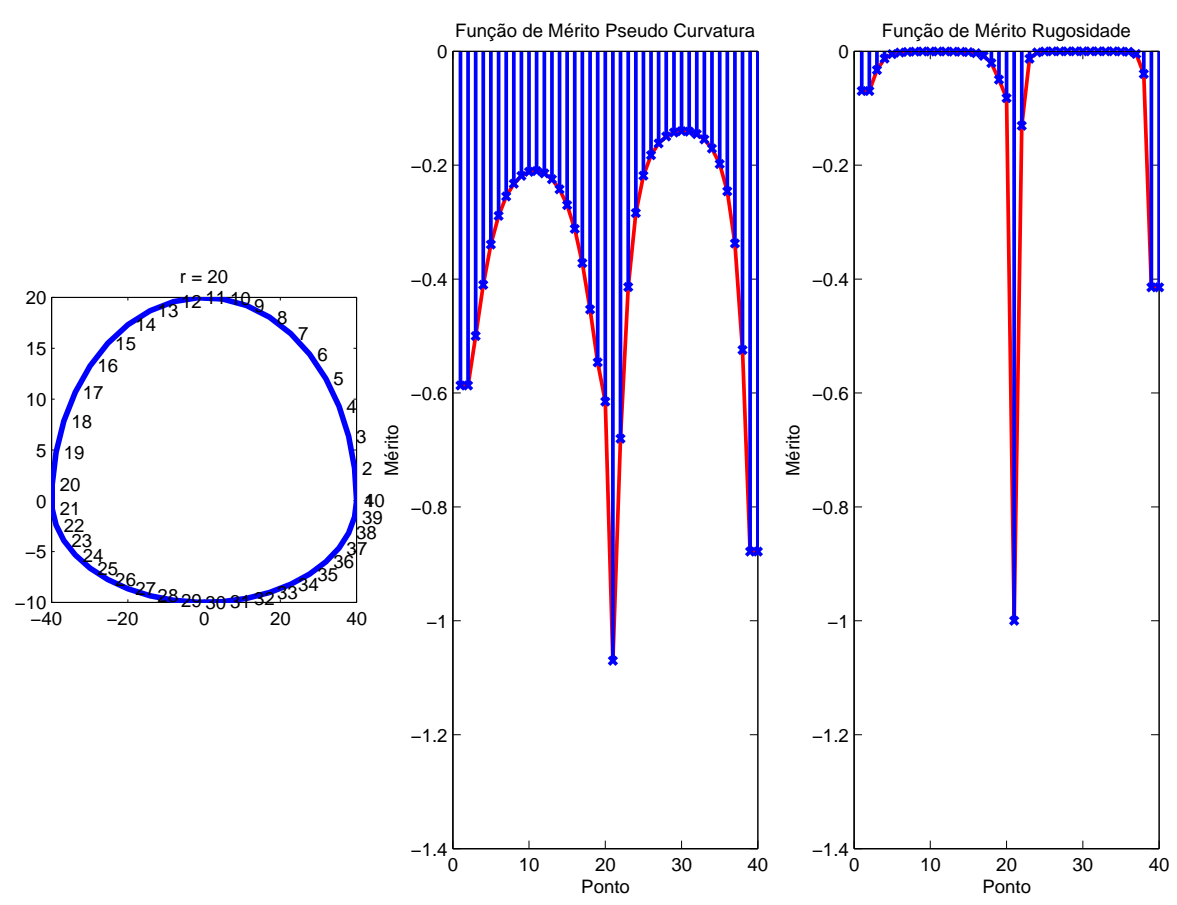

Figura 4.20: Méritos calculados por uso das funções pseudo-curvatura e rugosidade para contorno formado por duas semi-elipses concordantes 


\section{Capítulo 5}

\section{Conclusões}

Seja o modelo deformável paramétrico implementado pela minimização energética ou, pela generalização da força externa na formulação dinâmica, a evolução de seus pontos constituintes se dá sob a ação das forças internas e externas. A força interna atua de modo a impor ao contorno menores curvatura e alongamento ao passo em que a força externa atrai o contorno para as bordas de interesse. A ação combinada das duas naturezas de força, entretanto, eventualmente implica na evolução inadequada do contorno.

Conforme demonstraram os resultados, sob ação exclusiva das forças internas e externas conhecidas, os contornos deformáveis podem evoluir de modo a agrupar indevidamente seus pontos constituintes, não alcançar regiões côncavas, estacionar em mínimos locais e desprezar saliências.

Apesar de a análise superficial sugerir que uma abordagem conveniente ao problema seja a definição criteriosa dos parâmetros $\alpha$ e $\beta$ (2.4), os resultados demonstraram que a abordagem não é solução. A elevação demasiada dos parâmetros implica na obtenção de contornos arredondados e em seu eventual colapso.

As novas forças externas propostas em abordagem ao problema são, de fato, efetivas no sentido de aumentar a robustez da ferramenta mas o princípio que as norteia não contempla um problema intrínseco à metodologia de minimização da energia. O argumento comum às soluções propostas é o aumento da faixa de 
caputra da força externa como provedor de maior capacidade de guiar o contorno deformável aos contornos desejados. Essa abordagem, entretanto, é limitada. A convergência a mínimos locais, o agrupamento indesejado de pontos e o colapso do contorno foram verificados mesmo na presença de campos de força de grande qualidade.

A técnica proposta neste trabalho é singular em sua capacidade de dotar o contorno deformável de sensibilidade quanto às constribuições individuais dos pontos para a definição do aspecto. Conforme apurado, a minimização do déficite por pontos possibilita a sua utilização ótima aumenta a efetividade do campo de forças externas.

A força de corrugação constitui uma nova filosofia de abordagem ao problema e define uma nova natureza de força. Diferentemente das forças internas e externas, a força de corrugação atua nos pontos do contorno de modo a relocar seus pontos de forma ótima com vistas à representação de um dado aspecto. Trabalhos subsequentes devem ser dedicados a investigações complementares acerca de novas funções de mértio.

\subsection{Trabalhos Futuros}

A modelagem de frentes de avanço em rochas reservatório de petróleo é etapa crucial em análises críticas na engenharia de petróleo. A viabilidade de projetos de injeção de porte elevadíssimo, por exemplo, é fortemente dependente da consequente elevação do varrido areal do reservatório. A aplicação dos contornos deformáveis conforme proposto nesse trabalho viabilizou o emprego da técnica nos cenários heterogêneos e ruidosos típicos dos sinais representativos das rochas. Propõe-se o seguimento da pesquisa pelo emprego da metodologia em:

- predição de caminhos preferenciais (fingers);

- modelagem de frentes de avanço térmico na estimulação por combustão in-situ; 
- modelagem de frentes de avanço de filtrados;

- modelagem de frentes de avanço de acidificação;

- modelagem e classificação de estruturas de interesse em sinais sísmicos. 


\section{Referências Bibliográficas}

AMINI et al. (1990). AMINI, A., WEYMOUTH, T., \& JAIN, R. (1990). Using dynamic programming for solving variational problems in vision. IEEE Transactions on pattern analysis and machine intelligence, pages 855-867.

BERTERO et al. (1988). BERTERO, M., POGgiO, T., \& TORRE, V. (1988). Illposed problems in early vision. Proceedings of the IEEE, 76(8):869-889.

CHUANG \& LIE (2001). CHUANG, C. \& LIE, W. (2001). Automatic snake contours for the segmentation of multiple objects. In Circuits and Systems, 2001. ISCAS 2001. The 2001 IEEE International Symposium on, volume 2.

COHEN et al. (1993). COHEN, L., COHEN, I., \& CEREMADE, P. (1993). Finiteelement methods for active contour models and balloons for2-D and 3-D images. IEEE Transactions on Pattern Analysis and Machine Intelligence, 15(11):1131-1147.

DIAZ et al. (2007). DIAZ, J., ESPINA, V., GUERRERO, M., COLMENARES, O., \& MOSS, P. (2007). Successful Implementation of Coiled-Tubing Acid Tunneling Gives Operator a Viable Alternative to Conventional Stimulation Techniques in Carbonate Reservoirs. In SPE/ICoTA Coiled Tubing and Well Intervention Conference and Exhibition.

ERKOL et al. (2005). ERKOL, B., MOSS, R., STANLEY, R., STOECKER, W., \& HVATUM, E. (2005). Automatic lesion boundary detection in dermoscopy images using gradient vector flow snakes. Skin Research and Technology, 11(1):17-26. 
GEIGER et al. (1995). GEIGER, D., GUPTA, A., COSTA, L., \& VLONTZOS, J. (1995). Dynamic programming for detecting, tracking, and matchingdeformable contours. IEEE Transactions on Pattern Analysis and Machine Intelligence, 17(3):294-302.

GLIMM et al. (1983). GLIMM, J., LINDQUIST, B., MCBRYAN, O., PLOHR, B., \& YANIV, S. (1983). Front tracking for petroleum reservoir simulation. In SPE Reservoir Simulation Symposium.

GOLDENSTEIN et al. (2004). GOLDEnStein, S., VOGLER, C., \& VELHO, L. (2004). Adaptive deformable models. In Computer Graphics and Image Processing, 2004. Proceedings. 17th Brazilian Symposium on, pages 380-387.

HALDAR et al. (2008). HALDAR, S., AL-JANDAL, A., AL-DRIWEESH, S., SAID, R., ALSARAKBI, S., \& ESPINOSA, M. (2008). Evaluation of Rotary Jetting Tool Application for Matrix Acid Stimulation of Carbonate Reservoir in Southern Area Field of Saudi Arabia. In International Petroleum Technology Conference.

HAMARNEH \& GUSTAVSSON (2000). HAMARNEH, G. \& GUSTAVSSON, T. (2000). Combining snakes and active shape models for segmenting the humanleft ventricle in echocardiographic images. Computers in Cardiology 2000, pages 115-118.

JACOBSEN et al. (1995). JACOBSEN, J., BETHEL, E., DATTA-GUPTA, A., \& HOLLAND, P. (1995). Petroleum reservoir simulation in a virtual environment. In SPE Reservoir Simulation Symposium.

JALBA et al. (2004). JALBA, A., WILKINSON, M., \& ROERDINK, J. (2004). CPM: A deformable model for shape recovery and segmentation based on charged particles. IEEE Transactions on Pattern Analysis and Machine Intelligence, pages 1320-1335.

KASS et al. (1988). KASS, M., WITKIN, A., \& TERZOPOULOS, D. (1988). Snakes: 
Active contour models. International journal of computer vision, 1(4):321331.

LARTER et al. (2008). LARTER, S., ADAMS, J., GATES, I., BENNETT, B., \& HUANG, H. (2008). The origin, prediction and impact of oil viscosity heterogeneity on the production characteristics of tar sand and heavy oil reservoirs. Journal of Canadian Petroleum Technology, 47(1):52-61.

LEE \& ANDERSON (2006). LEE, T. \& ANDERSON, D. (2006). Checkerboard-Type Filtering for a Low-Power Gradient-Based Optical Flow Estimation System. In 2006 IEEE International Conference on Image Processing, pages 32853288 .

LIE \& CHUANG (2001). LIE, W. \& CHUANG, C. (2001). Fast and accurate snake model for object contour detection. Electronics Letters, 37(10):624-626.

MACDONALD et al. (1994). MACDONALD, D., AVIS, D., \& EVANS, A. (1994). Multiple surface identification and matching in magnetic resonance images. In Proceedings of SPIE, volume 2359, page 160.

MALLADI et al. (1995). MALLADI, R., SETHIAN, J., \& VEMURI, B. (1995). Shape modeling with front propagation: A level set approach. IEEE Transactions on Pattern Analysis and Machine Intelligence, 17(2):158-175.

MCINERNEY \& TERZOPOULOS (1995). MCINERNEY, T. \& TERZOPOULOS, D. (1995). Topologically adaptable snakes. In Computer Vision, 1995. Proceedings., Fifth International Conference on, pages 840-845.

MCINERNEY \& TERZOPOULOS (1996). MCINERNEY, T. \& TERZOPOULOS, D. (1996). Deformable models in medical image analysis. In Mathematical Methods in Biomedical Image Analysis, 1996., Proceedings of the Workshop on, pages $171-180$.

MENDEZ et al. (2005). MENDEZ, A., NEUMANn, L., PINTO, E., TORRES, R., FARIAS, R., \& ACOSTA, M. (2005). Achieving True Sandstone Reservoir 
Stimulation in Deepwater Horizontal Wells. In SPE Annual Technical Conference and Exhibition.

METAXAS \& KAKADIARIS (1996). METAXAS, D. \& KAKADIARIS, I. (1996). Elastically adaptive deformable models. Computer Vision ECCV 96, pages $550-559$.

MUMFORD \& SHAH (1988). MUMFORD, D. \& SHAH, J. (1988). Boundary detection by minimizing functionals. Image understanding.

NUNES et al. (2009). NUNES, M., BEDRIKOVETSKY, P., NEWBERY, B., FURTADO, C., SERRA DE SOUZA, A., \& PAIVA, R. (2009). Formation Damage Zone Radius and its Applications to Well Stimulation. In 8th European Formation Damage Conference.

PARAGIOS et al. (2004). PARAGIOS, N., MELLINA-GOTTARDO, O., \& RAMESH, V. (2004). Gradient vector flow fast geometric active contours. IEEE Transactions on Pattern Analysis and Machine Intelligence, 26(3):402-407.

PARK et al. (2001). PARK, H., SCHOEPFLIN, T., \& KIM, Y. (2001). Active contour model with gradient directional information: Directional snake. IEEE Transactions on Circuits and systems for video technology, 11(2):252-256.

ROTH \& BLACK (2007). ROTH, S. \& BLACK, M. (2007). On the spatial statistics of optical flow. International Journal of Computer Vision, 74(1):33-50.

SEO et al. (2004). SEO, K., CHOI, T., \& LEE, J. (2004). Adaptive color snake model for real-time object tracking. In 2004 IEEE International Conference on Robotics and Automation, 2004. Proceedings. ICRA'04, volume 1.

TERZOPOUlOS et al. (1988). TERZOPOUlOS, D., WITKIN, A., \& KASS, M. (1988). Symmetry-seeking models and 3D object reconstruction. International Journal of Computer Vision, 1(3):211-221.

VAN GINNEKEN et al. (2001). VAN GINNEKEN, B., FRANGI, A., STAAL, J., TER HAAR ROMENY, B., \& VIERGEVER, M. (2001). A non-linear graylevel appearance model improves active shape model segmentation. In Proc. 
of IEEE Workshop on Mathematical Methods in Biomedical Image Analysis (MMBIA), volume 2001. Citeseer.

WENNBERG et al. (2001). WENNBERG, K., VIKANE, O., KOTLAR, H., \& POITRENAUD, H. (2001). Successful Mud Acid Stimulations Maintain Productivity in Gravelpacked Wells at Heidrun. In SPE European Formation Damage Conference.

WERUAGA et al. (2004). WERUAGA, L., VERD, R., \& MORALES, J. (2004). Frequency Domain Formulation of Active Parametric Deformable Models (HTML). IEEE transactions on pattern analysis and machine intelligence, 26.

WILLIAMS \& SHAH (1992). WILLIAMS, D. \& SHAH, M. (1992). A Fast algorithm for active contours and curvature estimation* 1 . CVGIP: Image understanding, 55(1):14-26.

XU \& PRINCE (1998). XU, C. \& PRINCE, J. (1998). Snakes, shapes, and gradient vector flow. IEEE Transactions on image processing, 7(3):359-369.

XU et al. (2000). XU, C., YEZZI JR, A., \& PRINCE, J. (2000). On the relationship between parametric and geometric activecontours. In Signals, Systems and Computers, 2000. Conference Record of the Thirty-Fourth Asilomar Conference on, volume 1 .

YUNG (1997). YUNG, W. (1997). Enhanced snakes algorithm for contour detection. Tese de Doutoramento, Hong Kong Baptist University. 